\title{
Global Warming and Loss of Bearing Capacity of Permafrost: An Experimental Study on the Effects of Freezing/Thawing Cycles on a Silty Soil
}

\author{
E. Prina Howald ${ }^{*}$ and J. Torche
}

Department of Built Environment \& Geoinformation (EC+G), School of Engineering and Management Vaud (HEIG-VD), Yverdon-les-Bains, 1401, Switzerland

\begin{abstract}
One of the major effects of global warming is the thawing of permafrost. This phenomenon has several consequences on the affected environments, such as the loss of soil bearing capacity, the beginning of the seasonal cycles of freezing/thawing and an increase in the frequency of occurrence of natural hazards.

This paper focuses on the loss of soil bearing capacity. A preliminary experimental study was carried out to understand and quantify the changes in the behaviour of a silty soil subjected to a freezing / thawing cycle through a series of laboratory tests. After the soil used for the lab tests was characterised, many shear tests and oedometric tests were performed before, during and after freezing. The geotechnical parameters were deduced from the oedometric curves and Mohr-Coulomb diagrams obtained. The comparison of the results made it possible to observe the evolution of the soil parameters, i.e. the internal friction angle, the cohesion, and the oedometric curves.

All tests were carried out according to Swiss standards for laboratory testing.
\end{abstract}

Keywords: Freezing; Thawing; Shear test; Oedometric test; Permafrost; Silty soil.

\section{INTRODUCTION}

The phenomenon of thawing, as a consequence of global warming, affects permafrost (permanently frozen soils). In Europe, the Alpine regions are mostly characterised by the presence of permafrost. Switzerland, according to its geographical position and geomorphology, is clearly very concerned by this phenomenon.

The thawing of permafrost has three mains impacts:

- a loss of the soil bearing capacity, when the ground moves from the frozen state to the thawed state.

- an effect of fatigue problems on the infrastructures caused by the seasonal freezing I thawing cycles.

- an increase of natural hazards

This is why it is important to improve our knowledge on the behaviour of soil freezing/thawing. The swelling of soil during its freezing phase and its shrinkage during thawing phase can cause enormous damages to the built environment. Transport infrastructures, mountain resorts, and ski areas are the most exposed elements. Therefore, it is necessary to find a way to quantify the changes in the characteristics of a frozen soil when it is thawed. Moreover, the effects of cyclical

*Address correspondence to this author at the Department of Built Environment \& Geoinformation $(E C+G)$, School of Engineering and Management Vaud (HEIG-VD), Yverdon-les-Bains, 1401, Switzerland;

E-mail: erika.prinahowald@heig-vd.ch variations of the characteristics of soils can also cause fatigue problems on the infrastructures mentioned above.

Many studies have been performed on the freeze/thaw phenomenon. One of the biggest Swiss experiments on this phenomenon was carried out by Dysli [1]. This consisted of a life-size study of the freeze/thaw phenomenon on a road in a pit hall between 1975 and 1985 . These tests were requested by the Swiss Federal Roads Office (OFROU) in order to revise the road design standards for frost damage. Dysli's work focuses on the evolution of isotherms during frost, heat transfers, water displacement during the formation of ice lenses, the evolution of capillary pressure/suction, and soil swelling [1-3].

This paper describes and discusses the laboratory tests (shear tests, constant rate of strain oedometer tests, etc.) carried out on the silty soil in order to understand and quantify the loss of bearing capacity of a silty permafrost.

\section{METHODOLOGY}

The project which this paper is focused on attempted at quantifying the variations of the soil characteristics by means of an experimental study in the laboratory. The tests were performed on a thin soil. The soil studied was collected from the washing sludge of a lacustrine gravel near the Neuchâtel lake (Figure 1). All tests were carried out according to Swiss 
standards VSS (Schweizerischer Verband der Strassen) [9-16]. The soil is mainly composed of silt. This type of soil is ideal to study the impact of freezing/thawing because it is very sensitive to freeze (gelivity level: G4).

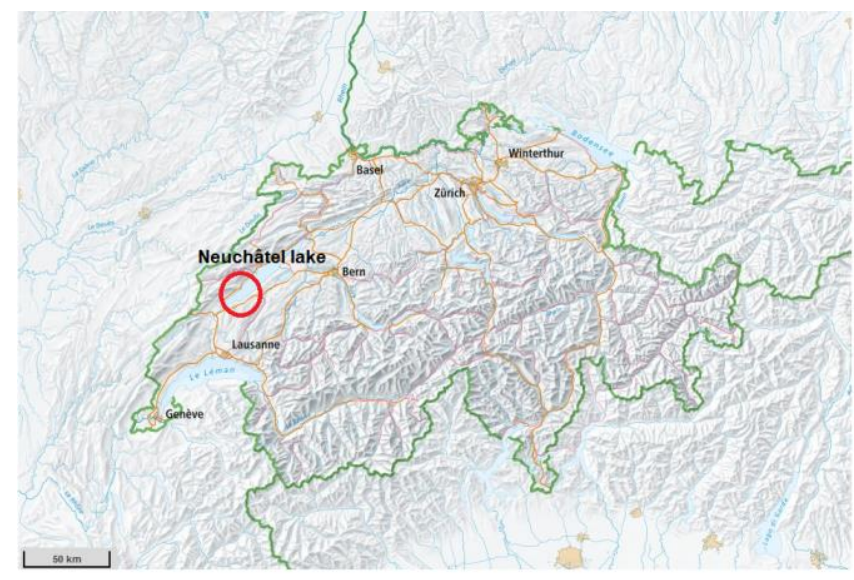

Figure 1: Swiss map.

This study is composed of three phases:

- a phase before the freezing

- a phase while the soil is frozen

- a phase after the thawing

First of all, the geotechnical parameters of the soil were evaluated by means of several tests. The results obtained in the first phase were considered as reference values and all results of the second and third phases were compared with them. This first, basic study included:

- a full granulometric analysis (sieving and sedimentometry)

- the determination of the Atterberg limits (liquidity and plasticity limits)

- the determination of the optimum water content according to the Proctor test.

- the determination of the bulk density by hydrostatic weighing

- $\quad$ direct shearing (Casagrande box)

- the performance of constant rate of strain (CRS) oedometer test

- photographic documentation of samples

Tests requiring a compact sample (shear and CRS tests) were performed on reconstituted soil cores, using a Proctor hammer with a compaction energy of 0.6
$\mathrm{MJ} / \mathrm{m}^{3}$ and a water content of $20.9 \%\left(\mathrm{~S}_{\mathrm{r}}=100 \%\right)$, in an A type proctor mold.

Afterwards, the samples were frozen at $-15^{\circ} \mathrm{C}$ for 18 days in a climatic chamber. The freezing time must be long enough to simulate the effect of permafrost and influence the characteristics of the soil. Tests on frozen soil included:

- a bulk density determination test just after the 18 days of freezing

- a shear test when the soil is frozen

- photographic documentation of samples

It was impossible to carry out a CRS test on the frozen soil because this test takes several days. The geotechnical laboratory is not equipped with a cold room in which the CRS test could have been carried out.

As a first approximation for overcoming this limit, samples were thawed in a waterproof box at the room temperature during 24 hours. Then, shear tests and CRS tests were performed on the thawed soil. The CRS test was conducted to obtain an assessment of soil compressibility when a soil is undergoing a freeze/ thaw phase. Although there were no CRS results on frozen soil as a reference point, it is reasonable to assume that frozen soil has compressibility lower or equal to its pre-freeze reference state. For this reason, the test was conducted on the thawed soil.

This procedure was applied on several specimens in order to find a correlation in the obtained results. The variations of the soil characteristics were deduced by superimposing shear curves and oedometric curves before freezing and after a cycle of freezing /thawing.

\section{SOIL CHARACTERISATION}

\subsection{Granulometry}

The granular distribution of the soil was obtained by sieving [15] (Figure 2) and sedimentometry [14] (Figure 3). The sieving process allowed to trace the granulometric curve to $0.063 \mathrm{~mm}$. Below $0.063 \mathrm{~mm}$, it was the sedimentometry process which gave the results. Sedimentometry was carried out by aerometer. Soil was mixed with demineralised water and an anti-flocculant $\left(15 \mathrm{~cm}^{3}\right.$ of sodium hexametaphosphate $\left.\left[\mathrm{NaPO}_{3}\right]_{6}\right)$. After stirring, a stopwatch was started. Then, the aerometer was immersed in the solution. Measurements on the aerometer were taken at specific times. 


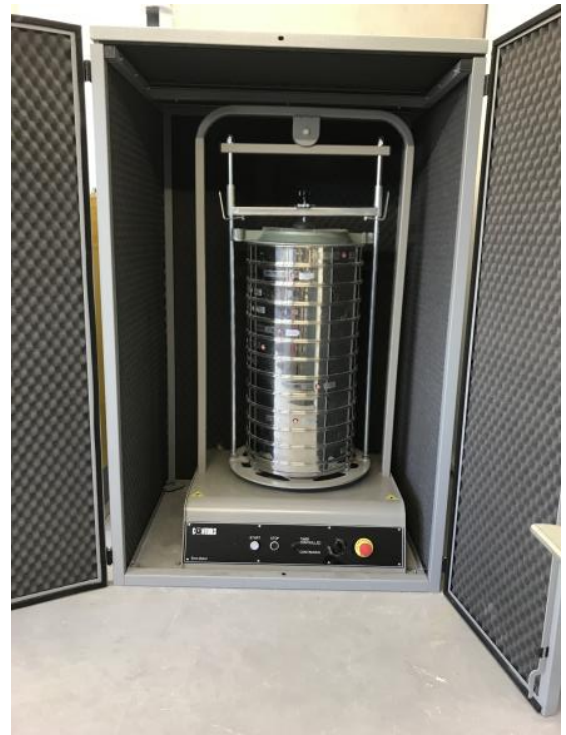

Figure 2: Sieving.

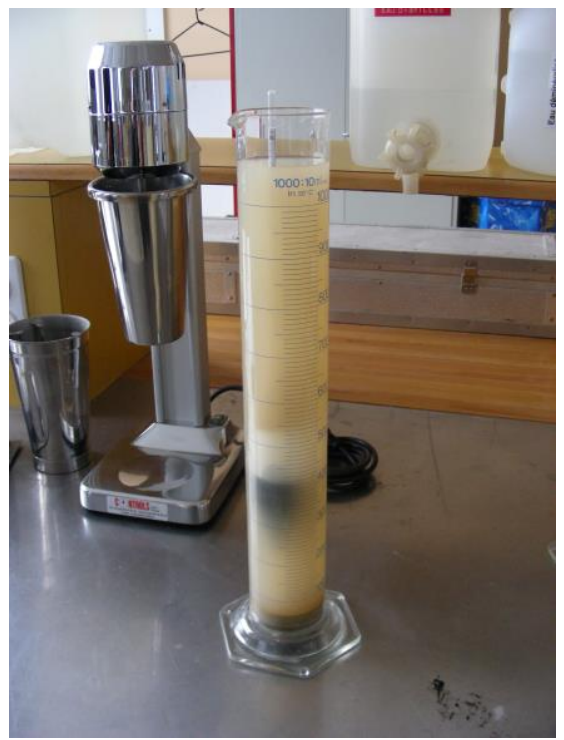

Figure 3: Sedimentometry.

The following relationship was used to calculate the particle diameter at each given time, for a temperature between $19^{\circ} \mathrm{C}$ and $20^{\circ} \mathrm{C}$ and a density between 2.65 $\mathrm{t} / \mathrm{m}^{3}$ and $2.75 \mathrm{t} / \mathrm{m}^{3}$.

$$
d=0.032 \cdot \sqrt{\frac{H_{r}}{t}}
$$

Figure 4 shows the particle size distribution. This distribution is between $0.002 \mathrm{~mm}$ and $0.3 \mathrm{~mm}$. The soil is composed by approximately $99 \%$ of silt. As mentioned in the introduction, silt is very sensitive to the effect of frost and that is the reason why this type of soil was chosen to carry out this study.

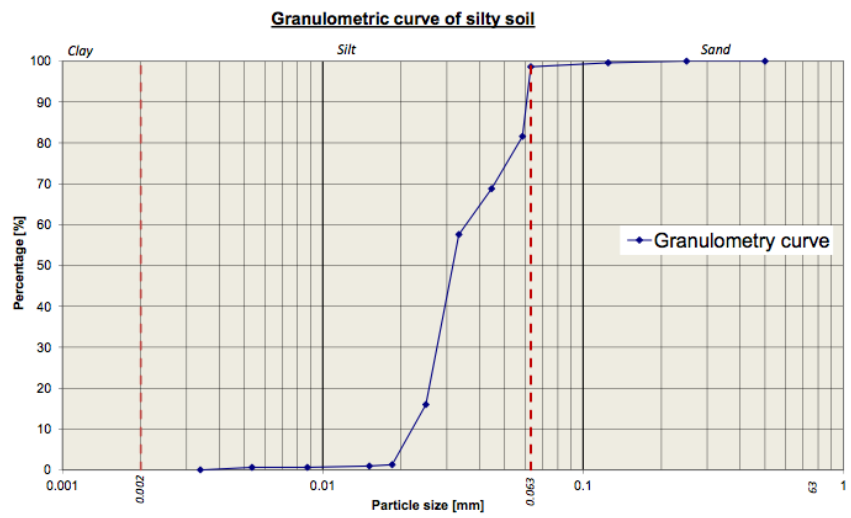

Figure 4: Granulometric curve.

\subsection{Atterberg Limits}

The Atterberg limits have been determined according to SN $670345 b$ [9]. The liquidity limit $W_{L}$ is the water content at which the soil changes from liquid state to plastic state. It was obtained by the Casagrande cup method (Figure 5). This method consists of measuring the water content for which the groove created in the cup closes for 25 shocks.

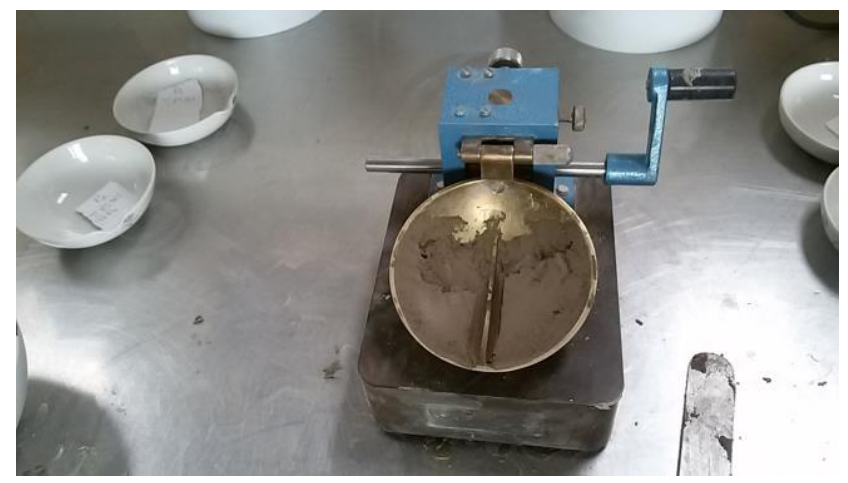

Figure 5: Atterberg limits.

The plasticity limit $\mathrm{W}_{\mathrm{P}}$ is the water content at which the soil changes from plastic state to solid state. It is obtained by creating a $3 \mathrm{~mm}$ diameter cylinder with the soil. Then, the cylinder is rolled on a porous stone until a clean break is obtained (Figure $\mathbf{6}$ ).

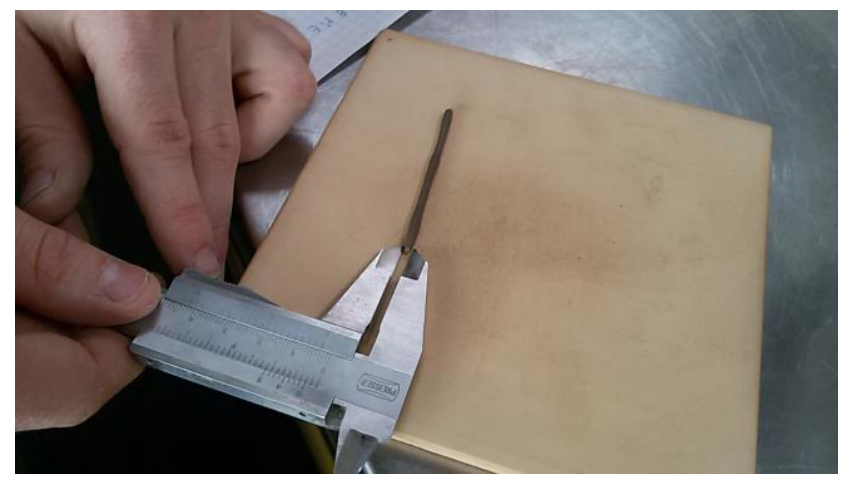

Figure 6: Classification of fine soils. 
The plasticity index $I_{P}$ is the difference between these two.

$$
I_{P}=W_{L}-W_{P}
$$

The values of $\mathrm{W} L$ and $I \mathrm{P}$ are necessary for soil classification according to USCS.

Table 1 shows the values of six Atterberg limits. The average liquidity limit was $29.9 \%$ and the average plasticity limit was $20.4 \%$. The plasticity index was $9.5 \%$.

Table 1: Atterberg Limits Results

\begin{tabular}{|c|c|c|c|}
\hline Tests & WL [\%] & WP [\%] & IP [\%] \\
\hline \hline $\mathbf{1}$ & 30.4 & 17.6 & 12.8 \\
\hline $\mathbf{2}$ & 28.3 & 18.5 & 9.8 \\
\hline $\mathbf{3}$ & 28.5 & - & - \\
\hline $\mathbf{4}$ & 31.4 & 25.5 & 5.9 \\
\hline $\mathbf{5}$ & 30.4 & 20.3 & 10.1 \\
\hline $\mathbf{6}$ & 30.1 & 20.3 & 9.8 \\
\hline Average & $\mathbf{2 9 . 9}$ & $\mathbf{2 0 . 4}$ & $\mathbf{9 . 5}$ \\
\hline
\end{tabular}

According to the results, the soil is at the boundary of silty clay $\mathrm{CL}$ and silt ML (Figure 7). However, the granulometry test allowed concluding that the soil is a silt (ML). According to Table 1 of VSS 70 140b [16], the susceptibility level of frozen soil studied is G4 (ML and $\left.I_{P}<12\right)$, which is very sensitive to frost.

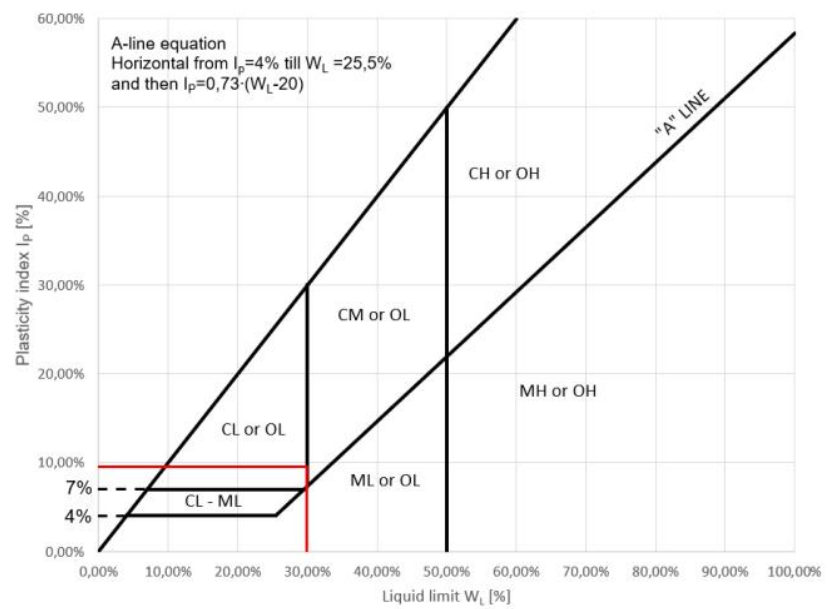

Figure 7: Classification of fine soils.

\subsection{Proctor test}

The Proctor test is used to know the optimal water content of the soil and the optimal dry bulk density.
These values can be read on the Proctor curve. The curve is obtained by correlating five points with increasing water content and their respective bulk density. SN 670 330-2 [10] was applied to carry out this test.

A Proctor point is given by the compaction in a proctor mold, whose volume is known, of a material capped at $16 \mathrm{~mm}$ with a compaction energy of $0.6 \mathrm{MJ} / \mathrm{m}^{3}$. This corresponds to a three-layer compaction in three layers of 25 strokes each, using a $2.5 \mathrm{~kg}$ hammer (Figure 8) and a drop height of $305 \mathrm{~mm}$ in a type A proctor mold (approximately $935 \mathrm{~cm}^{3}$ ).

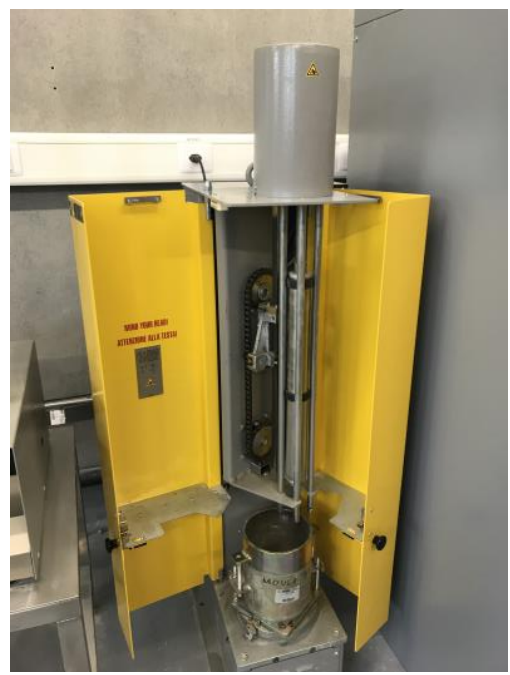

Figure 8: Proctor compactor.

The compaction energy is calculated according the following equation:

$$
E=\frac{P \cdot H \cdot n}{V}
$$

The optimal water content is of about $18 \%$ for the moist soil and $15 \%$ for the dry soil (Figure 9, Proctor curve). The optimal wet bulk density is of $2.03 \mathrm{t} / \mathrm{m}^{3}$; a value of $1.73 \mathrm{t} / \mathrm{m}^{3}$ was on the other hand found for the dry bulk density.

\subsection{Bulk Density}

The protocol SN 670 340-2 [12] was applied to carry out bulk density determination tests. This property can be measured using Archimedes theory and a hydrostatic weighing. In order to obtain the variation of the bulk density according to the water content, several tests were carried out with four different water content values, between $14 \%$ and $20 \%$. The water temperature was $25^{\circ} \mathrm{C}$ except for the first test, for which the temperature was $23^{\circ} \mathrm{C}$. 


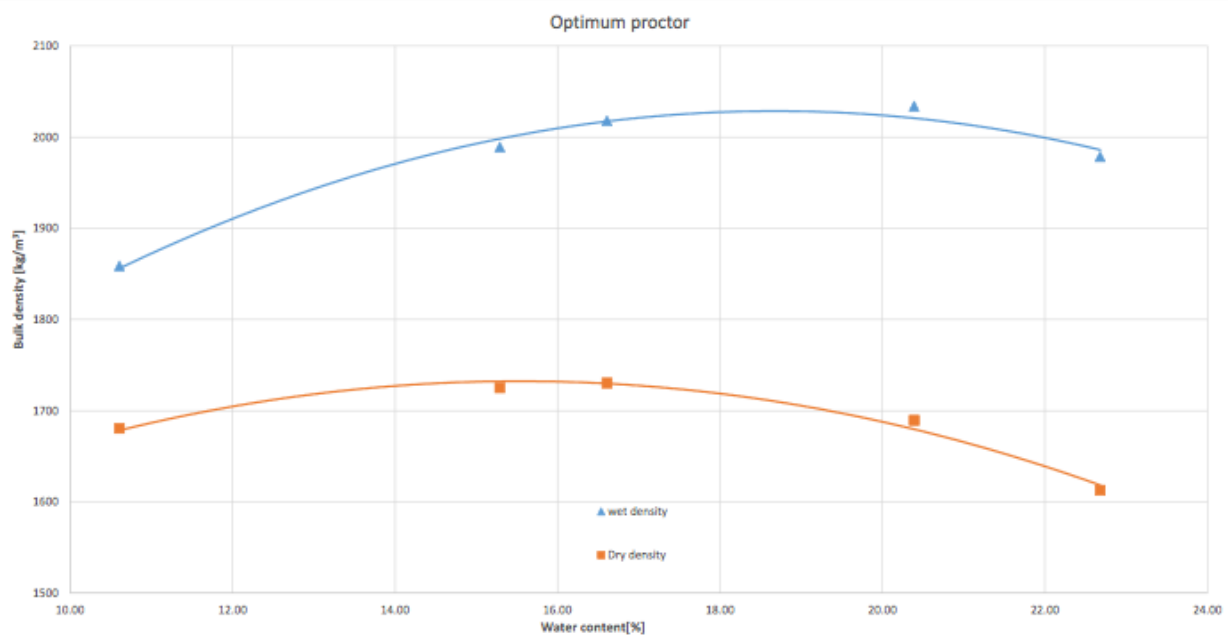

Figure 9: Proctor curve.

Table 2: Bulk Density Results

\begin{tabular}{|c|c|c|c|c|c|c|c|}
\hline $\mathbf{m}[\mathbf{g}]$ & $\mathbf{m}_{\mathbf{w}}[\mathbf{g}]$ & $\mathbf{m}_{\mathbf{g}}[\mathbf{g}]$ & $\mathbf{m}_{\mathbf{f}}[\mathbf{g}$ & $\mathbf{V}\left[\mathbf{c m}^{3}\right]$ & $\mathbf{\rho}\left[\mathbf{g} / \mathbf{c m}{ }^{3}\right]$ & $\mathbf{w}[\%]$ & $\mathbf{\rho}_{\mathbf{d}}\left[\mathbf{g} / \mathbf{c m}^{3}\right]$ \\
\hline \hline 1678 & 1705 & 830 & 1678 & 847.16 & 1.98 & 14.00 & 1.74 \\
\hline 1757 & 1790 & 899 & 1757 & 856.97 & 2.05 & 16.96 & 1.75 \\
\hline 1783 & 1802 & 898 & 1783 & 885.57 & 2.01 & 18.77 & 1.70 \\
\hline 1843 & 1867 & 915 & 1843 & 928.15 & 1.99 & 19.77 & 1.66 \\
\hline
\end{tabular}

Table 2 shows the results obtained. The bulk density presented a little variation, between $1.98 \mathrm{~g} / \mathrm{cm}^{3}$ and $2.05 \mathrm{~g} / \mathrm{cm}^{3}$. Therefore, for all the following tests, the assumed value of bulk density for the soil studied was $2.01 \mathrm{~g} / \mathrm{cm}^{3}$, which corresponds to $19.7 \mathrm{kN} / \mathrm{m}^{3}$ (rounded to $20 \mathrm{kN} / \mathrm{m}^{3}$ ).

\subsection{Reconstituted Sample}

Samples were reconstituted with a saturation degree of $100 \%$. The soil moisture content for $\mathrm{S}_{\mathrm{r}}=100 \%$ was calculated using the Proctor test results. The value of the solid particle density $\gamma_{\mathrm{s}}$ is generally between 26 and $27 \mathrm{kN} / \mathrm{m}^{3}$. According to these values and the results of the Proctor test, the degree of saturation $\mathrm{S}_{r}$ was calculated for a water content of $18 \%$, giving these results: $\mathrm{S}_{\mathrm{r}}=93 \%$ with $\gamma_{\mathrm{s}}=26 \mathrm{kN} / \mathrm{m}^{3}$ and $\mathrm{S}_{\mathrm{r}}=88 \%$ with $\gamma_{\mathrm{s}}=27 \mathrm{kN} / \mathrm{m}^{3}$. In order to achieve a $100 \%$ degree of saturation, the required water content should be between $20.3 \%$ and $21.5 \%$. The average of these two values was taken into account for the following tests, i.e. a water content of $20.9 \%$.

Samples were reconstituted using a Proctor hammer with a compaction energy of $0.6 \mathrm{MJ} / \mathrm{m}^{3}$ and a water content of $20.9 \%$ in an A type proctor mold.
Samples were usually in good condition. However, a manufacturing defect was present on all samples. Figures 10 and 11 show a groove at $11 \mathrm{~cm}$. This was due to the extension of the proctor mold. Indeed, when removing the samples from the mold, the extension was removed. In order to avoid tearing off the top of the sample, rotational movements had to be performed, which sheared the top of the core and left this mark visible.

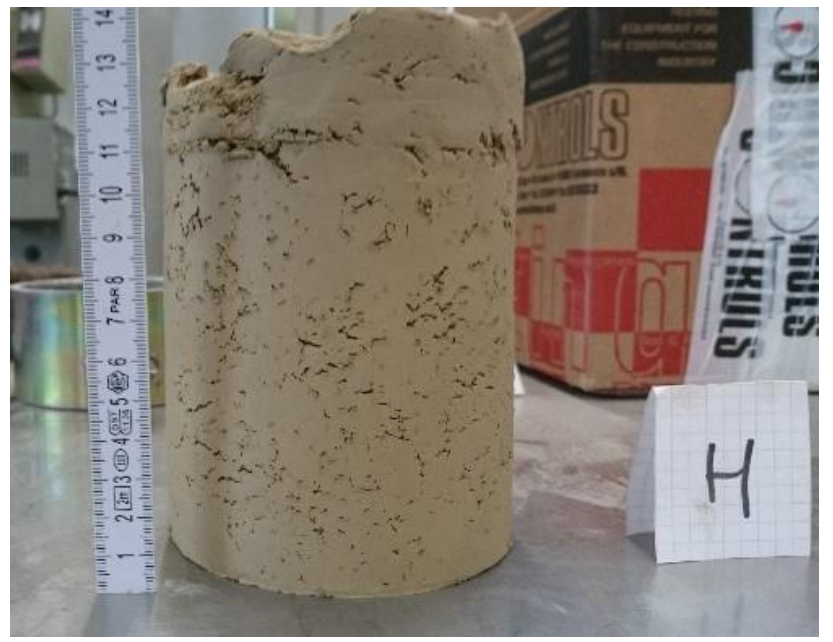

Figure 10: Sample $\mathrm{H}$ before freezing. 


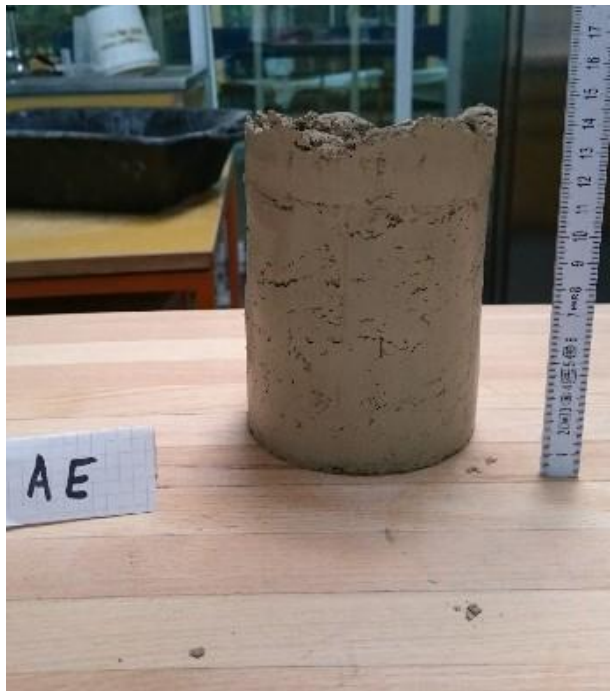

Figure 11: Sample AE before freezing.

Samples had a relatively homogeneous appearance; however, some voids can be observed on the surface. All samples had this appearance, so it can be concluded that the sample preparation method was good.

A brief microscopic analysis was carried out. This is an observation of a sample taken with a cutter blade on a thin blade at $6.4,16$ and 40 zoom. The objective of this analysis was also a visual description, but at a higher resolution. This is to obtain a reference comparison point before freezing, to observe possible changes in the soil studied after a thawing cycle.

The texture of the sample under the microscope is similar in every way to what can be observed on a core. A homogeneous matrix with some voids was observed (Figures 12, 13 and 14).

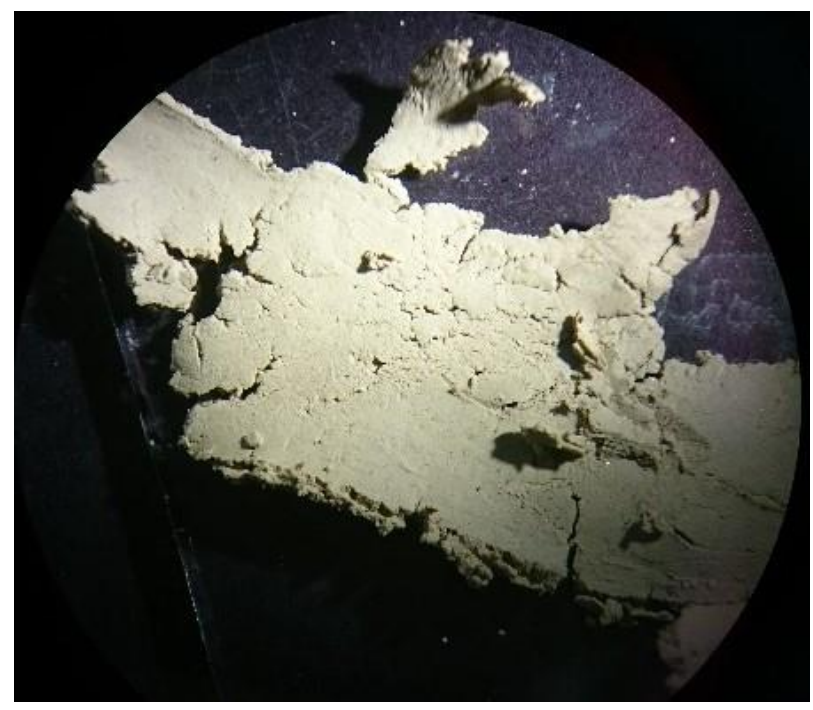

Figure 12: Zoom of 6.4 .

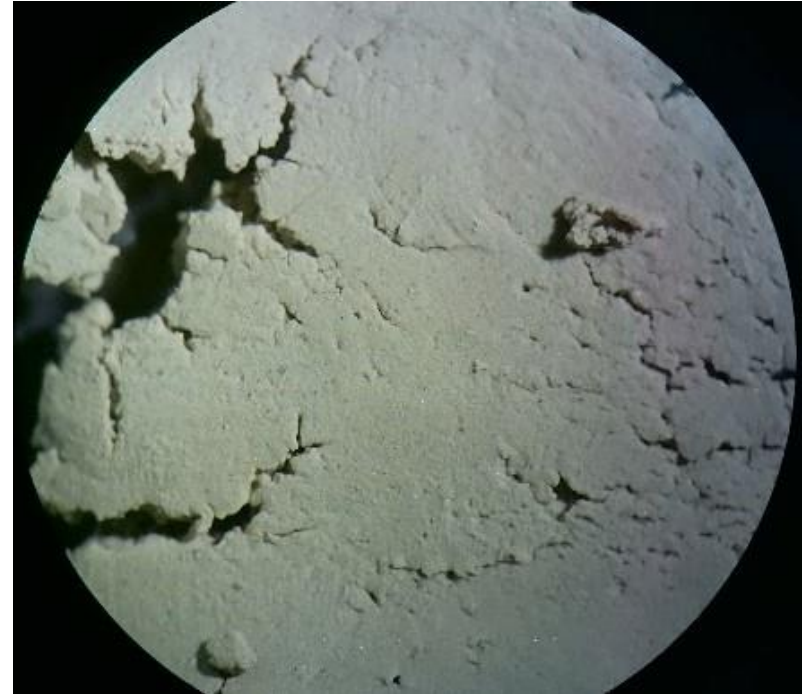

Figure 13: Zoom of 16.

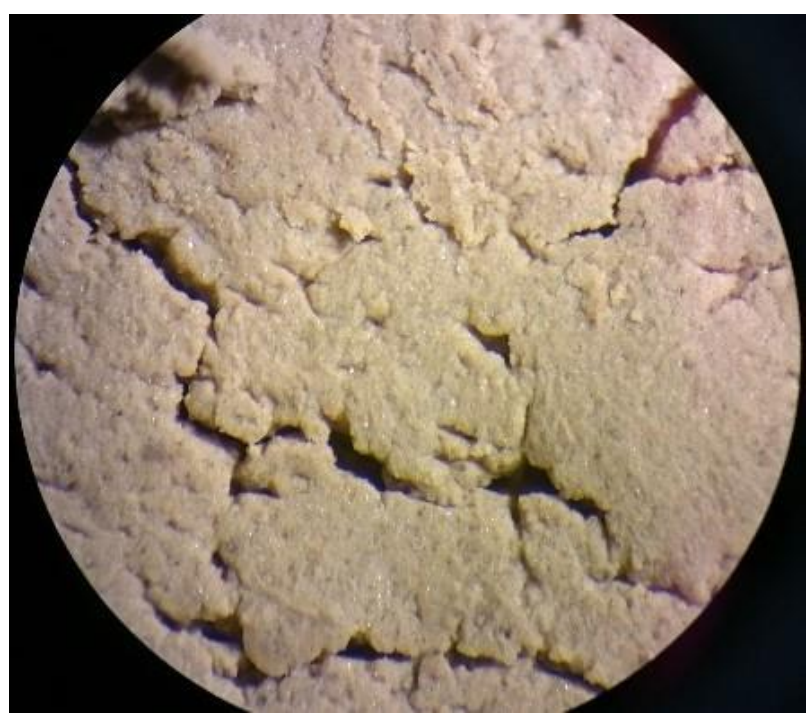

Figure 14: Zoom of 40.

\subsection{Shear Test}

Direct shear tests were carried out to determine the shear resistance of the soil. These included the cohesion c (in $\mathrm{kN} / \mathrm{m}^{2}$ ) and the internal friction angle $\varphi$ (in ${ }^{\circ}$ ). The test is governed by the standard SN 670 340-10 [11]. Tests were performed in a sliding steel box. Samples were cut with a cutting square mold $(L=$ $60 \mathrm{~mm}$ and $\mathrm{h}=20 \mathrm{~mm}$ ) then put in the shear box. The shear was induced by the displacement of the lower part of the shear box at a speed of $1 \mathrm{~mm} / \mathrm{min}$, while a normal stress was applied (Figure 15 and 16). The shear speed was the same as in the test that was performed when the sample was frozen. The normal stress corresponds to the soil's initial stress. However, the studied soil was collected from the washing sludge of a lacustrine gravel, which is why the depth of soil 
sampling was estimated. The estimated depth was 3.5 meters, with the initial stress of $70 \mathrm{kN} / \mathrm{m}^{2}$.

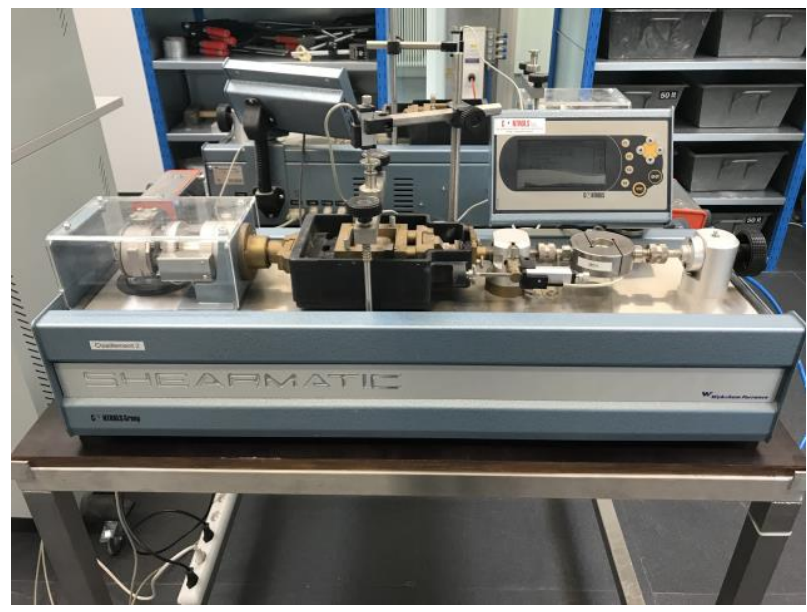

Figure 15: Shear test (1).

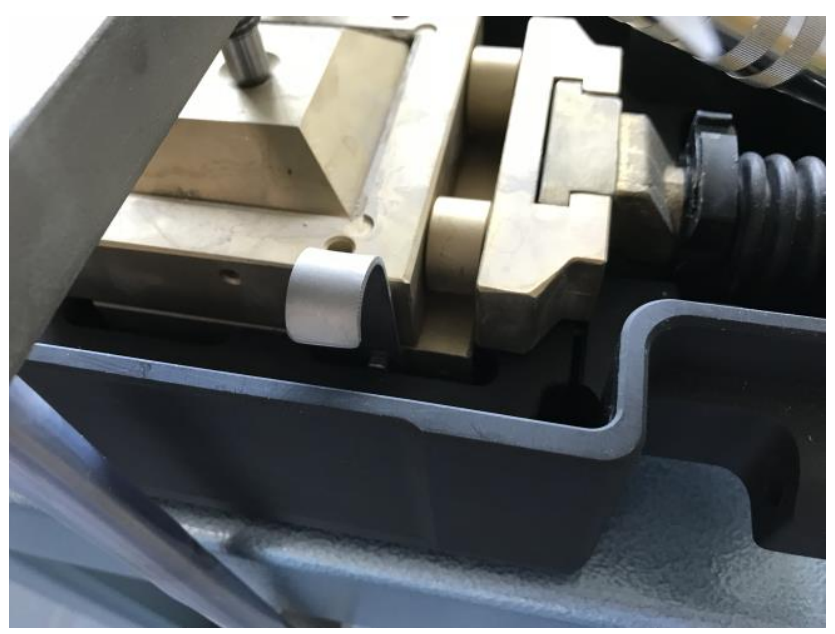

Figure 16: Shear test (2).

Three points are necessary to draw the MohrCoulomb envelope. Figure 17 shows the MohrCoulomb envelope of three shear tests. As a reminder, the cohesion is the ordinate at the origin of the regression curve and the angle of internal friction is the slope of the curve.

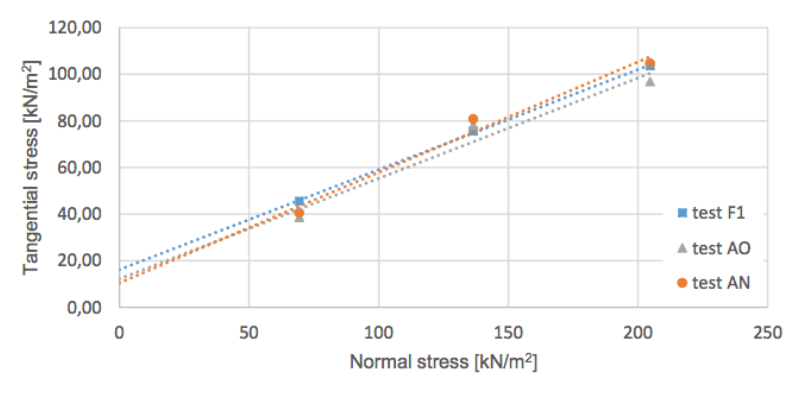

Figure 17: Mohr-Coulomb diagram.
This soil, therefore, presented a cohesion $c=12.95$ $\mathrm{kN} / \mathrm{m}^{2}$ and an angle of internal friction $\varphi=23.98^{\circ}$ (Table 3).

Table 3: Results of Shear Test Before Freezing

\begin{tabular}{|c|c|c|c|c|}
\hline Sample & $\begin{array}{c}\text { Cohesion } \\
{\left[\mathbf{k N} / \mathbf{m}^{2}\right]}\end{array}$ & $\begin{array}{c}\text { Internal } \\
\text { friction } \\
\text { angle }\left[{ }^{\circ}\right]\end{array}$ & $\begin{array}{c}\text { Correlation } \\
\mathbf{r}^{2}[-]\end{array}$ & $\begin{array}{c}\text { Water } \\
\text { Content } \\
{[\%]}\end{array}$ \\
\hline \hline F1 & 16.16 & 23.24 & 0.9994 & 21.24 \\
\hline AO & 12.22 & 23.32 & 0.9586 & 21.00 \\
\hline AN & 10.47 & 25.37 & 0.9775 & 20.17 \\
\hline Average & $\mathbf{1 2 . 9 5}$ & $\mathbf{2 3 . 9 8}$ & $\mathbf{0 . 9 7 8 5}$ & $\mathbf{2 0 . 8 0}$ \\
\hline
\end{tabular}

\subsection{Constant Rate of Strain Oedometer Test}

A constant rate of strain (CRS) oedometer test was carried out according to the SN $670340-5$ [13] in order to evaluate the compression parameters of the soil. These included the oedometric curve and the compression/swelling indexes, $\mathrm{C}_{\mathrm{c}}$ and $\mathrm{C}_{\mathrm{s}}$.

The CRS equipment (Figure 18) used a thin stainless steel oedometric ring $\left(\varnothing_{\text {int }}=71.4 \mathrm{~mm}, \mathrm{~h}=20 \mathrm{~mm}\right.$ and $\mathrm{t}=2.5 \mathrm{~mm})$. CRS test was performed with 18 loading stages of 24 hours each. The following stress values (in $\mathrm{kN} / \mathrm{m}^{2}$ ) were used for the test: $5,10,20,40$, $70,40,20,10,25,50,100,200,400,800,400,200$, 100,50 . The initial stress of the drill core was about $70 \mathrm{kN} / \mathrm{m}^{2}$ (depth estimated at 3.5 meters and bulk density of $20 \mathrm{kN} / \mathrm{m}^{3}$ ). The sample was made artificially and, for this reason, a first loading until the initial stress was applied, then the stress was released. Afterwards, a second loading until $800 \mathrm{kN} / \mathrm{m}^{2}$ was applied, then the stress was released and the test was finished.

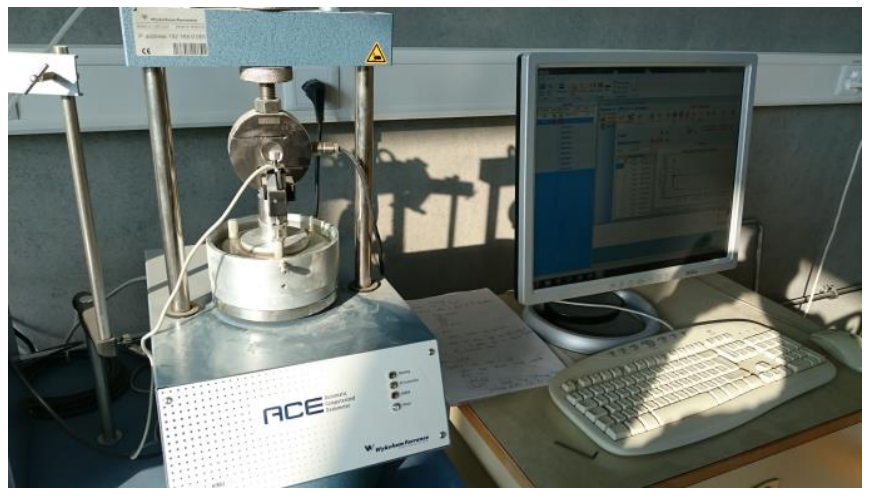

Figure 18: CRS test.

Figures 19, 20 and Table 4 show the results of the test. The initial void ratio of the soil is 0.680 and the compression/swelling indexes, $\mathrm{C}_{\mathrm{c}}$ and $\mathrm{C}_{\mathrm{s}}$, are $8.3 \cdot 10^{-2}$ 


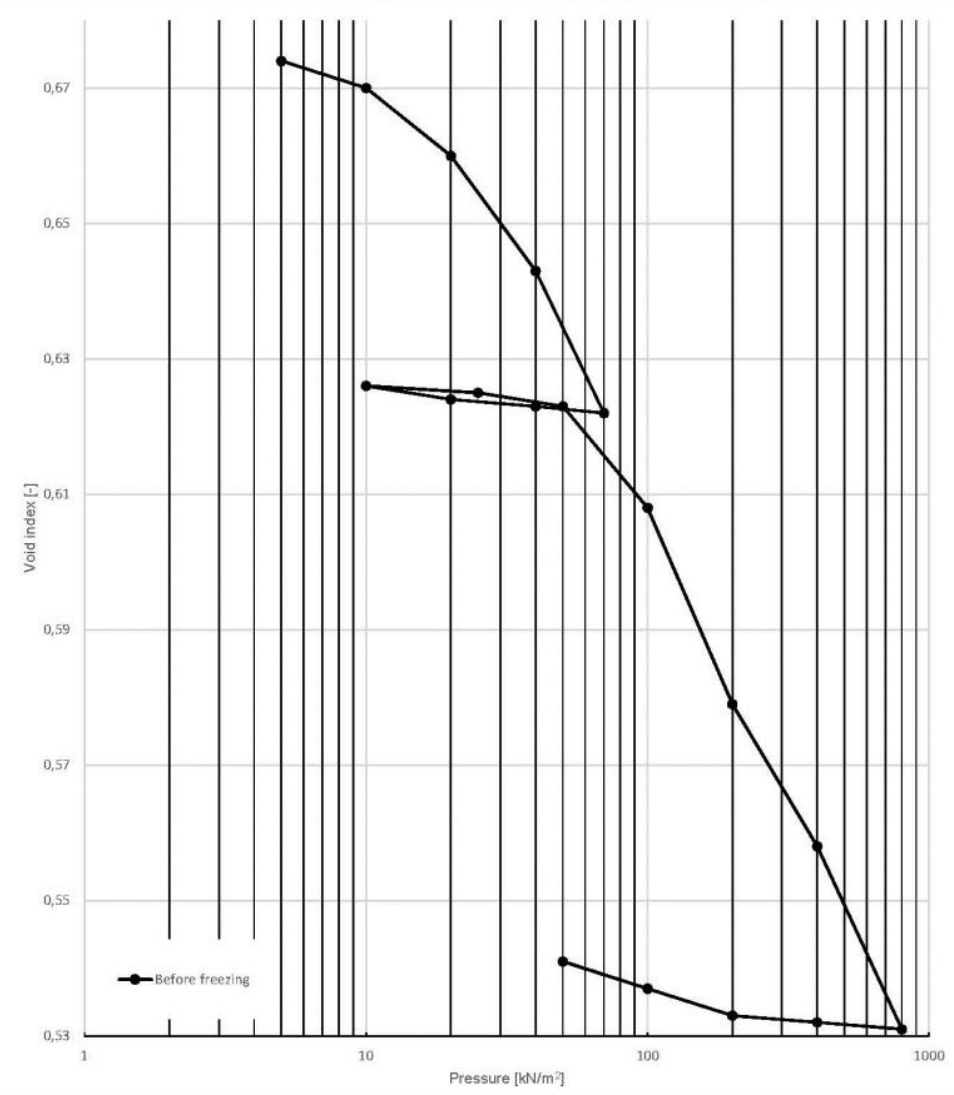

Figure 19: Initial oedometric curve.

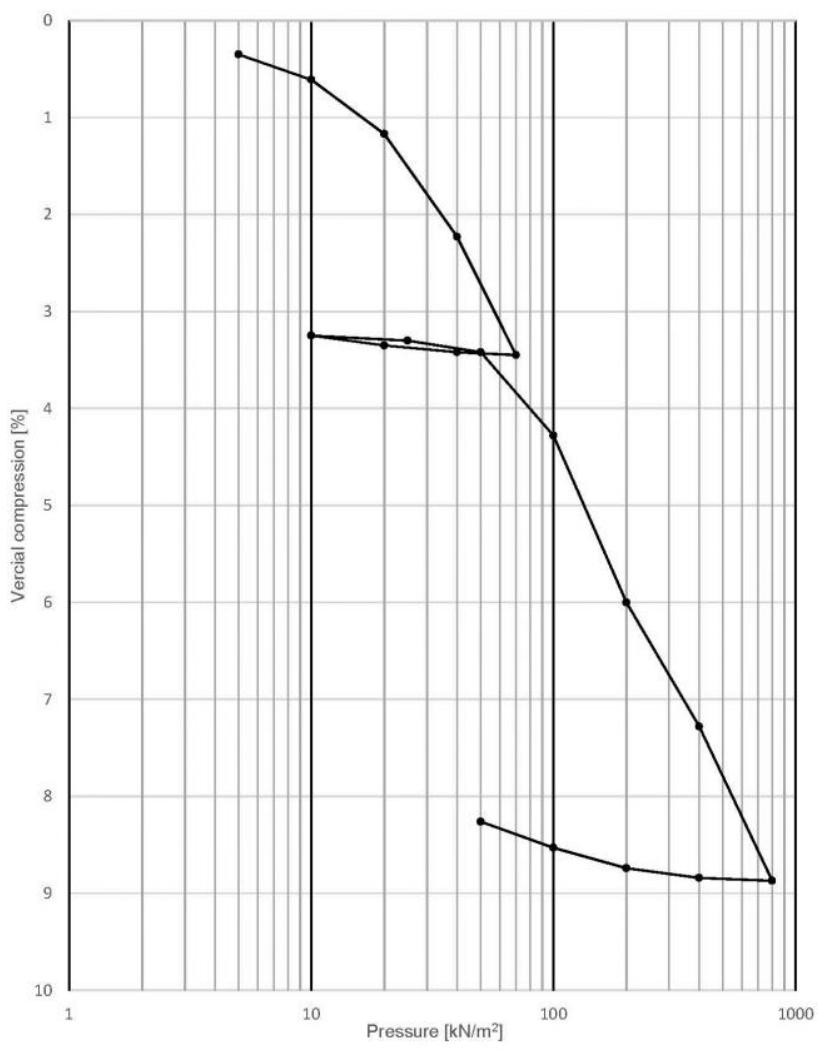

Figure 20: Vertical compression of the soil. 
Table 4: Compression Parameters

\begin{tabular}{|c|c|c|c|c|}
\hline Stress level [kN/m2] & e1 [-] & $\Delta \sigma[\mathrm{kN} / \mathrm{m} 2]$ & $\mathrm{mv}[\mathrm{m} 2 / \mathrm{MN}]$ & Eoed [MN/m2] \\
\hline \multirow{2}{*}{5} & \multirow{2}{*}{0.674} & & & \\
\hline & & 5 & 0.476 & 2.100 \\
\hline 10 & 0.670 & \multirow{2}{*}{10} & \multirow{2}{*}{0.595} & \multirow{2}{*}{1.680} \\
\hline \multirow{2}{*}{20} & \multirow{2}{*}{0.66} & & & \\
\hline & & \multirow{2}{*}{20} & \multirow{2}{*}{0.506} & \multirow{2}{*}{1.976} \\
\hline \multirow{2}{*}{40} & \multirow{2}{*}{0.643} & & & \\
\hline & & 30 & 0.417 & 2.400 \\
\hline 70 & 0.622 & \multirow{2}{*}{-} & \multirow{2}{*}{ - } & \multirow{2}{*}{ - } \\
\hline \multirow[b]{2}{*}{40} & \multirow[b]{2}{*}{0.623} & & & \\
\hline & & - & - & - \\
\hline 20 & 0.624 & & \multirow{2}{*}{-} & \multirow{2}{*}{ - } \\
\hline 10 & 0.626 & & & \\
\hline & & 15 & 0.040 & 25.200 \\
\hline 25 & 0.625 & 25 & 0.048 & 21.000 \\
\hline 50 & 0.623 & 50 & 170 & 5900 \\
\hline 100 & 0.608 & & & \\
\hline & & 100 & 0.173 & 5.793 \\
\hline 200 & 0.579 & 200 & 0.062 & 16.000 \\
\hline 400 & 0.558 & 100 & 040 & 24880 \\
\hline 800 & 0.531 & & & \\
\hline & & - & - & - \\
\hline 400 & 0.532 & - & - & - \\
\hline 200 & 0.533 & & & \\
\hline & & - & - & - \\
\hline 100 & 0.537 & - & - & - \\
\hline 50 & 0.541 & & & \\
\hline
\end{tabular}

and $4.3 \cdot 10^{-3}$, respectively. The soil void ratio was between 0.674 and 0.531 for a stress between $5 \mathrm{kN} / \mathrm{m}^{2}$ to $800 \mathrm{kN} / \mathrm{m}^{2}$. The maximum vertical compression was $8.87 \%$ for a stress level of $800 \mathrm{kN} / \mathrm{m}^{2}$

Compressibility coefficient, $\mathrm{m}_{\mathrm{v}}$, and oedometric moduls, $E_{o e d}$ were calculated according to the following equations:

$$
\begin{gathered}
m_{v}=\frac{\Delta e}{(1+e) \cdot \Delta \sigma} \\
E_{\text {oed }}=\frac{1}{m_{v}}
\end{gathered}
$$

Compressibility coefficient results for stress levels from 10 to $25 \mathrm{kN} / \mathrm{m}^{2}$ and 25 to $50 \mathrm{kN} / \mathrm{m}^{2}$ were 
unusually low. The reason is due to the first loading to reproduce the initial stress. The first loading reduced the soil void ratio which resulted in a decrease of the compressibility coefficient.

The soil oedometric modulus, $E_{\text {oed, }}$ was determined equal to $2.400 \mathrm{MN} / \mathrm{m}^{2}$ for the initial stress. This value increased to $24.889 \mathrm{MN} / \mathrm{m}^{2}$ for a stress level of 800 $\mathrm{kN} / \mathrm{m}^{2}$.

\section{TEST ON FROZEN SOIL}

After the soil characterisation and the definition of the shear strength and the compressibility properties of the soil before freezing (reference case), the specimens prepared were frozen in an air-conditioned cabinet. This step was necessary to simulate the permafrost conditions. The choice of the temperature and the duration of the freezing process required several tests. At first, a temperature of $-15^{\circ} \mathrm{C}$ and a duration of 3 days had been fixed. However, the duration was not sufficient to change the geotechnical parameters. For this reason, the duration was fixed at 18 days, the same duration of a CRS test.

\subsection{Pictures Description}

Figures 21 and 22 show the same samples seen in Figures 10 and 11, but after the 18 days of freezing. The first freezing samples were kept in a plastic bag in order to maintain the water content. Nevertheless, this manipulation was discarded because the plastic bag induced an adsorption phenomenon. Adsorbed water froze on the surface of the sample. Figure 21 shows the ice on the surface.

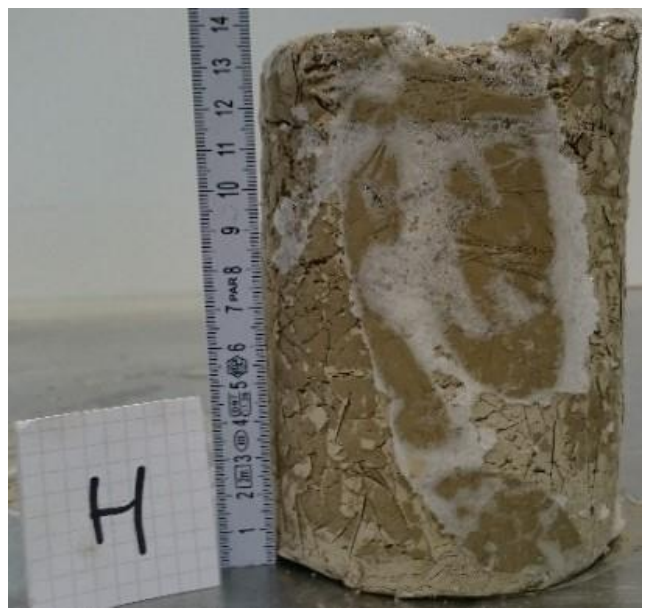

Figure 21: Sample H frozen.

Samples after the freezing phase presented a laminated appearance. This was due to the formation of many vertical cracks. These cracks were relatively wide and reached 1 to $2 \mathrm{~mm}$ in width. Samples were very friable because cracks weakened the surface.

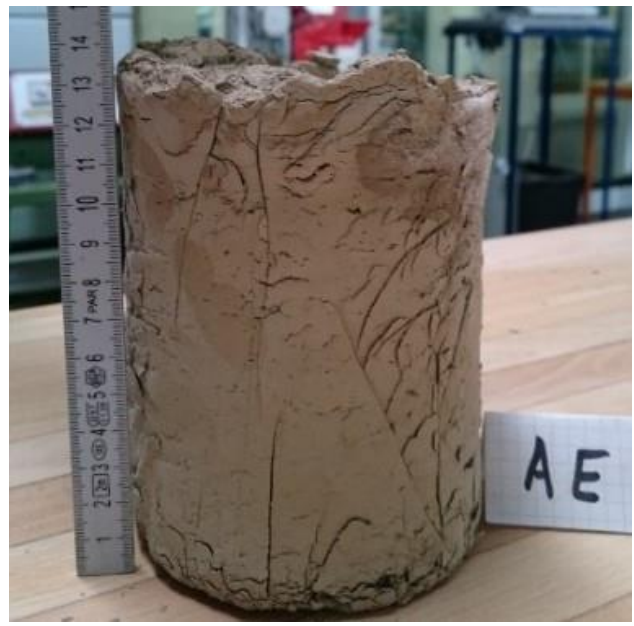

Figure 22: Sample AE frozen.

The appearance of the exterior of the frozen sample under the microscope was similar to that of the cores. There were many cracks in which ice was observed (Figures 23, 24 and 25). This same ice melted quickly during the observation. The thawing of ice lenses induced the opening of cracks, as well as the movement of water along the cracks. For this reason, some humidity can be observed in the above-mentioned figures.

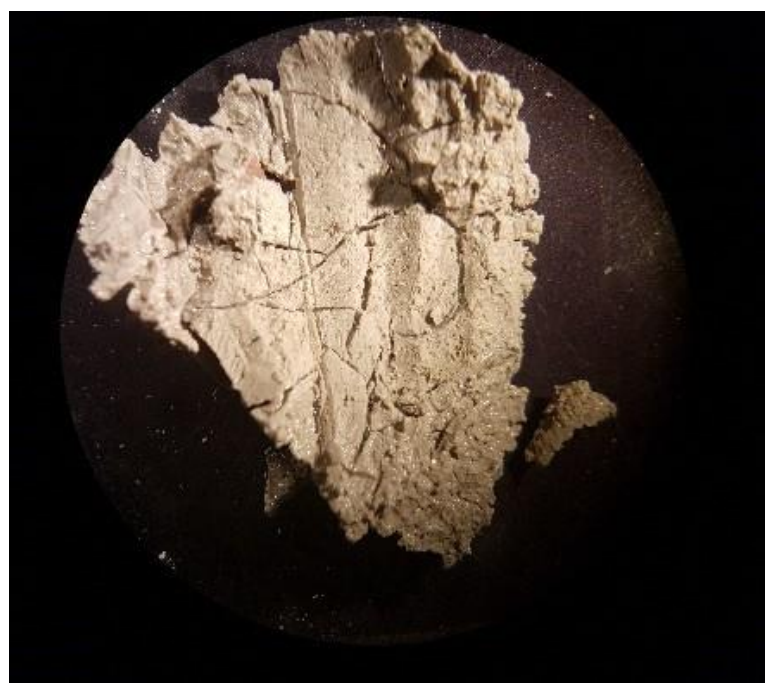

Figure 23: Zoom of 6.4 .

\subsection{Bulk Density}

Six bulk density tests were carried out by hydrostatic weighing on the frozen soil. Table 5 summarises the results. The water temperature was $22^{\circ} \mathrm{C}$. 


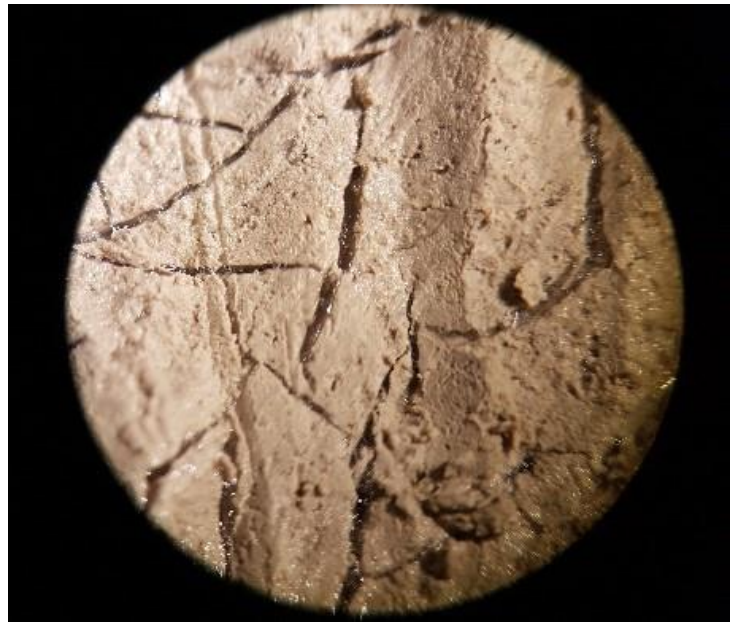

Figure 24: Zoom of 16.

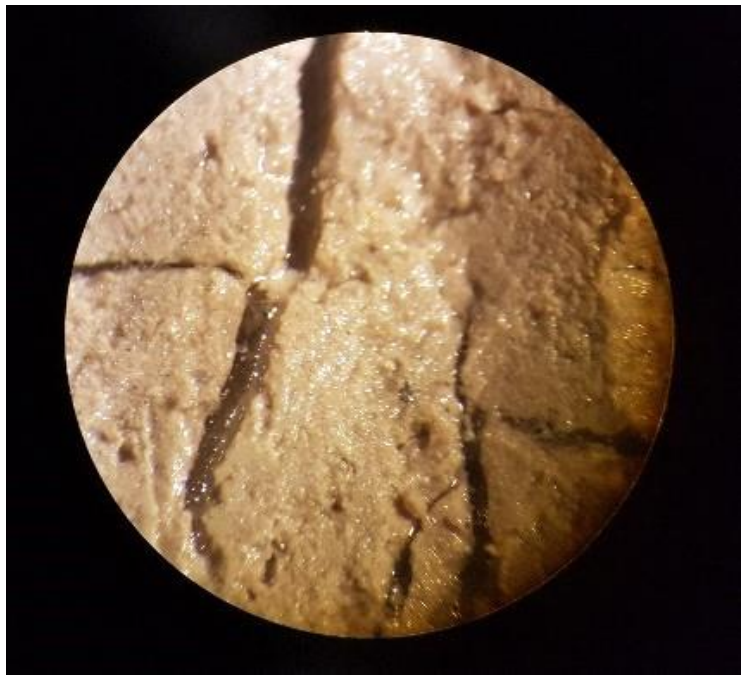

Figure 25: Zoom of 40.

The samples were very brittle; it was relatively difficult to apply paraffin without losing a little material. The mass measurements of the sample therefore had a slight error, because a little part of the material fell during the waxing operation. This is why the measured mass was slightly greater than the actual mass of the sample. This error was of the order of a few grams maximum, less than $0.5 \%$.

The bulk density was $1.93 \mathrm{~g} / \mathrm{cm}^{3}$ at the water content of $20.9 \%\left(S_{r}=100 \%\right)$. Therefore, the bulk density was $4.0 \%$ lower than the reference state $\left(2.01 \mathrm{~g} / \mathrm{cm}^{3}\right)$.

\subsection{Shear Test}

A direct shear test was performed just after the sample had left the climatic chamber in order to evaluate the geotechnical parameters $c$ and $\varphi$ on the frozen soil.

This test was very difficult to carry out for two reasons:

- the stiffness of the frozen soil

- the time to perform this test before the soil thawed

The soil resistance was too high to execute the sampling manually. Therefore, the sampling had to be done by a mechanical press. Unfortunately, the force applied by the press was too strong and damaged the cutting mold (Figure 26 and 27). Because of this, only one of such tests was carried out.

Another problem was the thawing of the sample during the test. A standard shear test lasts several hours. As the laboratory is not equipped to do this test in a cold room, it was impossible to perform a shear test on the frozen soil and avoid the thawing of the sample during the test. Therefore, the shear speed was increased to $1 \mathrm{~mm}$ per minute. The same shear speed was used for the shear tests before and after freezing. Tables 6 and 7 summarise the results and Figure 28 shows the Mohr-Coulomb diagram.

Table 5: Bulk Density Results

\begin{tabular}{|c|c|c|c|c|c|c|}
\hline Sample & $m[g]$ & $m_{w}[g]$ & $m_{g}[g]$ & $\mathrm{V}\left[\mathrm{cm}^{3}\right]$ & $\rho\left[\mathrm{g} / \mathrm{cm}^{3}\right]$ & $\rho_{d}\left[\mathrm{~g} / \mathrm{cm}^{3}\right]$ \\
\hline I & 1985.4 & 1995.6 & 951.0 & 1035.60 & 1.92 & 1.59 \\
\hline$M$ & 1993.2 & 2032.5 & 957.0 & 1034.23 & 1.93 & 1.59 \\
\hline 0 & 2183.9 & 2207.2 & 1055.0 & 1128.88 & 1.93 & 1.60 \\
\hline \multirow[t]{2}{*}{$S$} & 2112.1 & 2140.4 & 1026.0 & 1085.44 & 1.95 & 1.61 \\
\hline & & & & Average & 1.93 & 1.60 \\
\hline
\end{tabular}




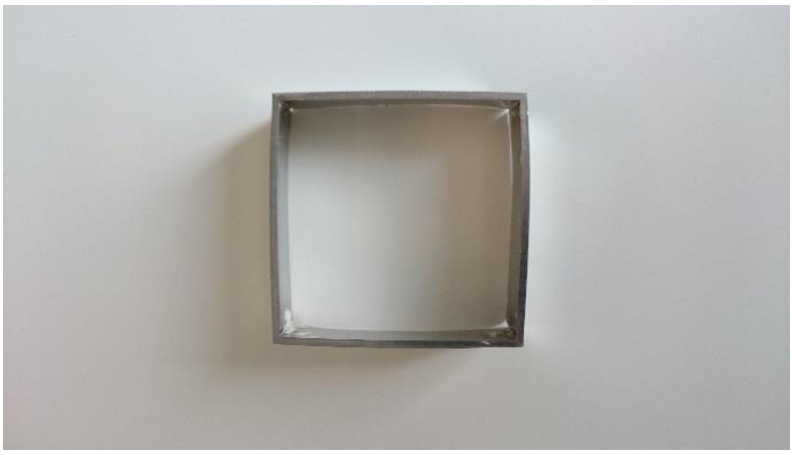

Figure 26: Broken cutting mold (1).

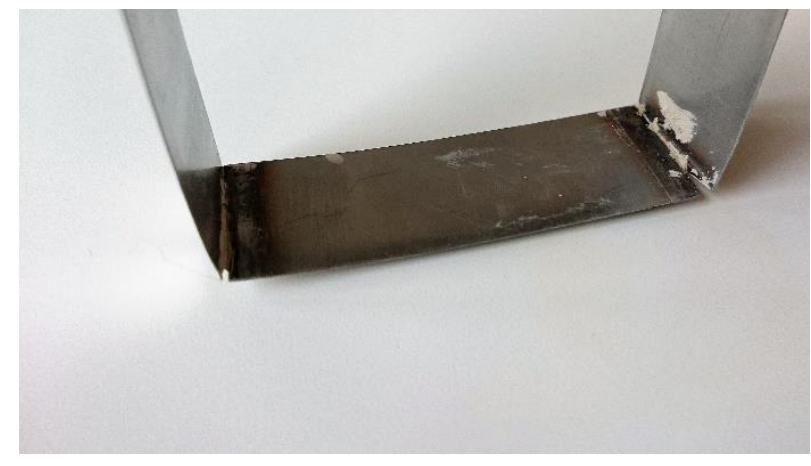

Figure 27: Broken cutting mold (2).

The three points of the Mohr Coulomb diagram were aligned along the linear trend given by the equation:

$$
y=0.5154 \cdot x+56.327
$$

The correlation obtained was excellent (>98\%). The soil cohesion in the frozen state is of $56.33 \mathrm{kN} / \mathrm{m}^{2}$. The angle of internal friction is equal to the slope of the regression line, i.e.:

$$
\varphi=\arctan (0.5154)=27.27^{\circ}
$$

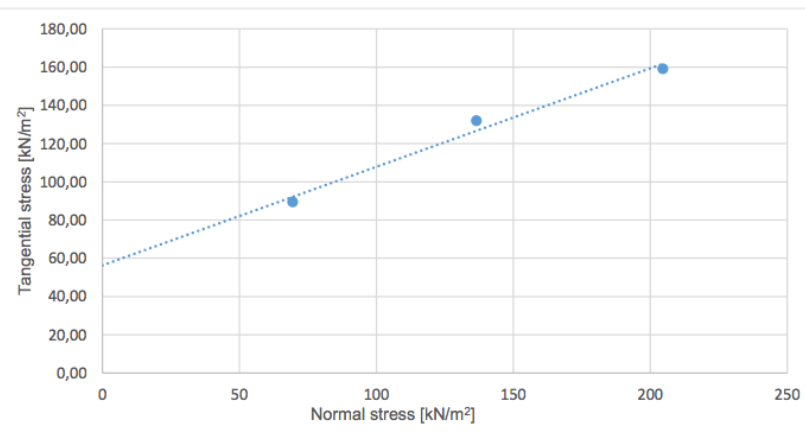

Figure 28: Mohr-Coulomb diagram of frozen soil.

The angle of internal friction increased by $13.7 \%$ and the cohesion increased by $335 \%$ in relation to the initial state.

The water content at the end of the test was lower than the desired value $(20.9 \%)$. This difference is due to the formation of ice lenses and water migration during the freezing process. These undesirable effects could not be totally avoided.

\section{TEST AFTER THAWING}

After 18 days of freezing at $-15^{\circ} \mathrm{C}$, samples were brought out of the climatic chamber in order to be put in waterproof box. Samples were thawed at the room temperature (approximately $25^{\circ} \mathrm{C}$ ). The time necessary to completely thaw samples was 24 hours.

\subsection{Pictures Description}

The overall state of the drill cores after the frozen phases was poor; strong degradations were visible on all the specimens. The sample underwent a significant change. Cracking caused by the appearance and thawing of ice lenses was important. The size of the cracks varied, some were very small, and others large

Table 6: Values of Shear Test on Frozen Soil

\begin{tabular}{|c|c|c|c|c|c|c|}
\hline Point & $\begin{array}{c}\text { Tangential Stress } \\
{\left[\mathbf{k N} / \mathbf{m}^{2}\right]}\end{array}$ & $\begin{array}{c}\text { Normal Stress } \\
{\left[\mathbf{k N} / \mathbf{m}^{2}\right]}\end{array}$ & $\begin{array}{c}\text { Tare Weight } \\
{[\mathbf{g}]}\end{array}$ & $\begin{array}{c}\text { Wet Mass + Tare } \\
{[\mathbf{g}]}\end{array}$ & $\begin{array}{c}\text { Dry Mass + Tare } \\
{[\mathrm{g}]}\end{array}$ & $\begin{array}{c}\text { Water Content } \\
{[\%]}\end{array}$ \\
\hline \hline 1 & 89.44 & 69.4 & 64.81 & 199.14 & 178.71 & 17.94 \\
\hline 2 & 131.94 & 136.5 & 100.57 & 242.79 & 221.21 & 17.89 \\
\hline 3 & 159.17 & 204.6 & 84.47 & 222.39 & 201.04 & 18.32 \\
\hline
\end{tabular}

Table 7: Geotechnical Parameters of Frozen Soil

\begin{tabular}{|c|c|c|c|c|}
\hline Sample & Cohesion $\left[\mathrm{kN} / \mathrm{m}^{2}\right]$ & Internal Friction Angle [ $\left.{ }^{\circ}\right]$ & Correlation $\mathbf{r}^{2}[-]$ & Water Content $[\%]$ \\
\hline \hline $\mathrm{A}$ & 56.33 & 27.27 & 0.9832 & 18.05 \\
\hline
\end{tabular}


and crossed the entire sample. Figures 29 and $\mathbf{3 0}$ show an extreme degradation of the sample. A crack about $1 \mathrm{~cm}$ wide can be seen on pictures. This sample collapsed on itself under the effect of gravity shortly after taking this picture and was obviously unusable for CRS tests and direct shear tests.

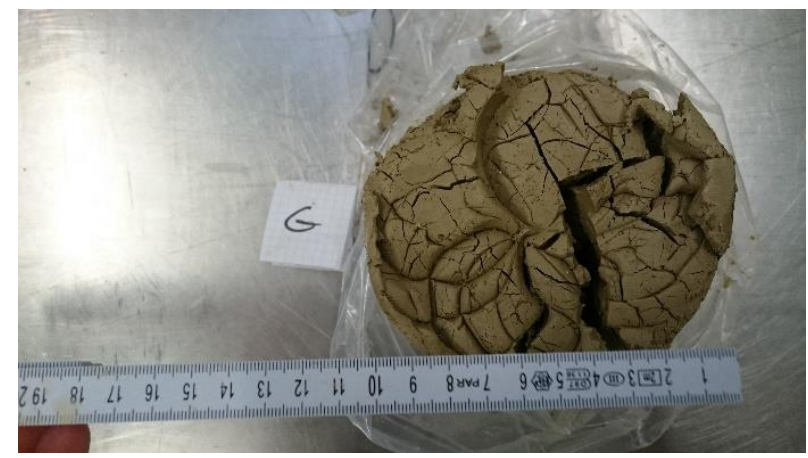

Figure 29: Sample G after thawing (1).

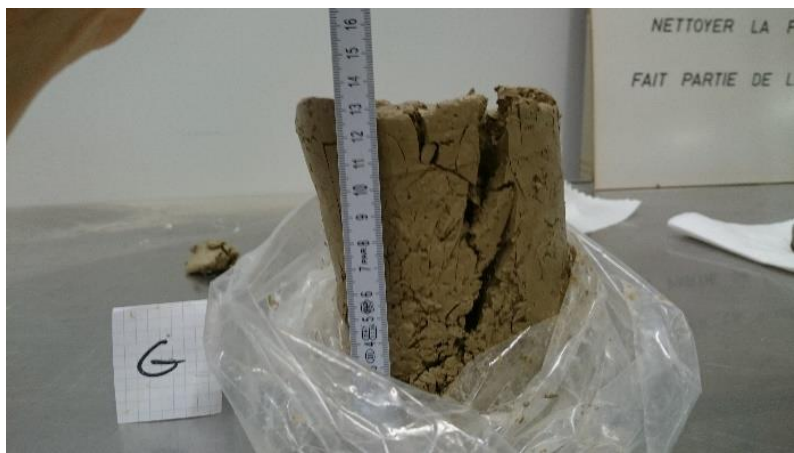

Figure 30: Sample G after thawing (2).

Smaller cracks, sometimes not visible, could also be very troublesome when sampling for the CRS tests and direct shear tests. Figure $\mathbf{3 1}$ shows the cracks and void caused by the formation and then thawing of ice

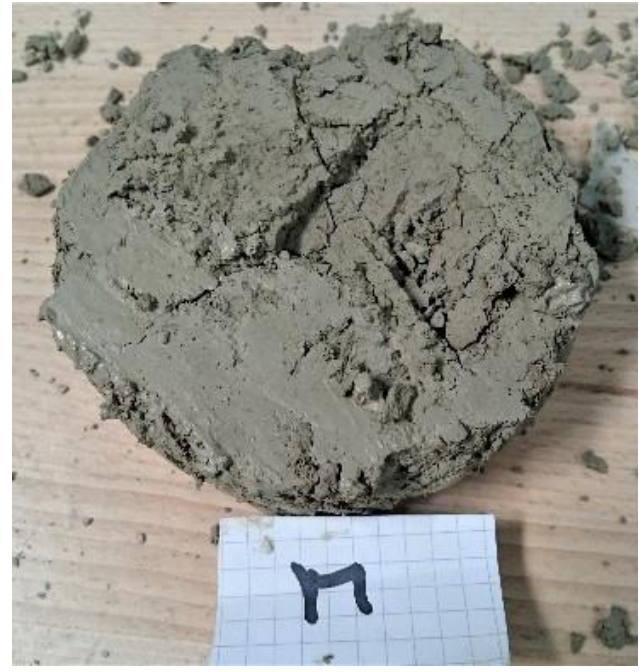

Figure 31: Sample M after thawing. lenses. These degradations were only visible after the sample was cut for the direct shear tests. In total, approximately forty percent of samples were destroyed or became unusable during the thawing step. Other minor damages were noticed. The surface of the samples detached in sheets, as it can be seen in Figures 32 and 33.

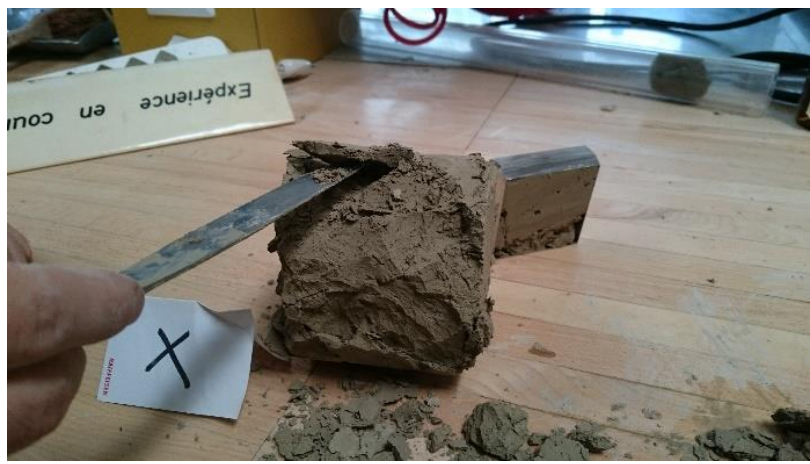

Figure 32: Sample $X$ after thawing (1).

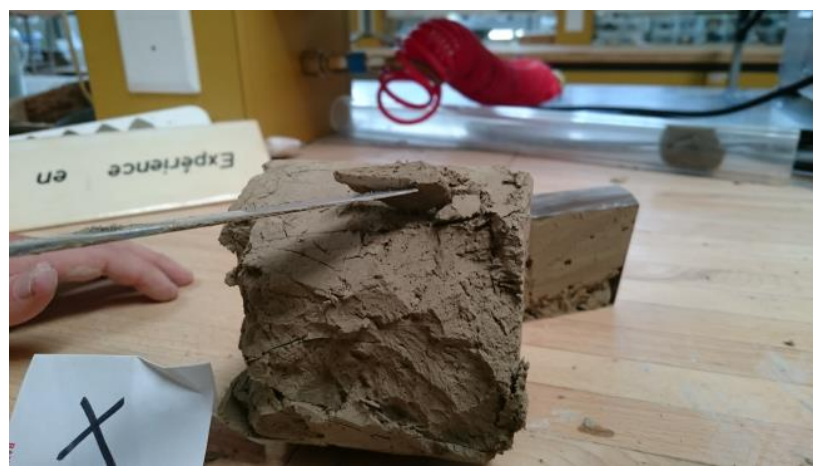

Figure 33: Sample $X$ after thawing (2).

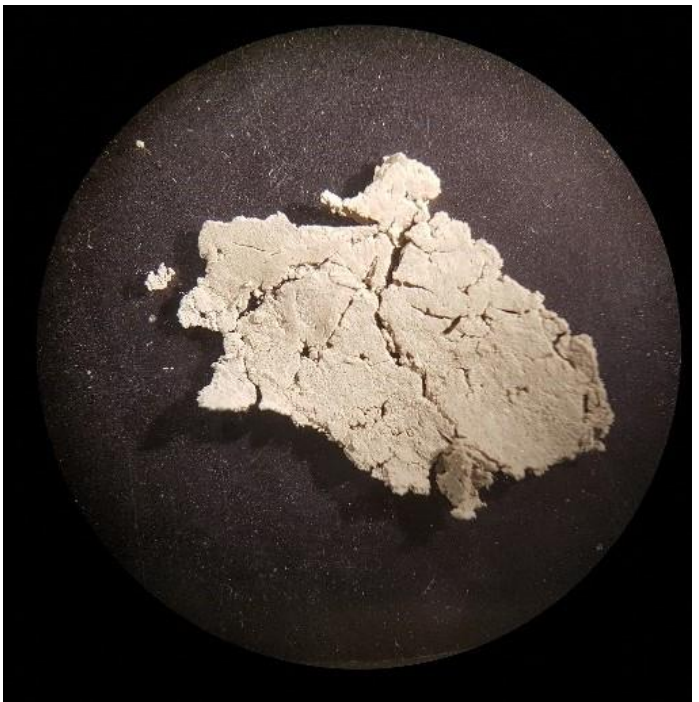

Figure 34: Zoom of 6.4

The microscopic study confirmed the macroscopic observations. More cracks were observed than in the 


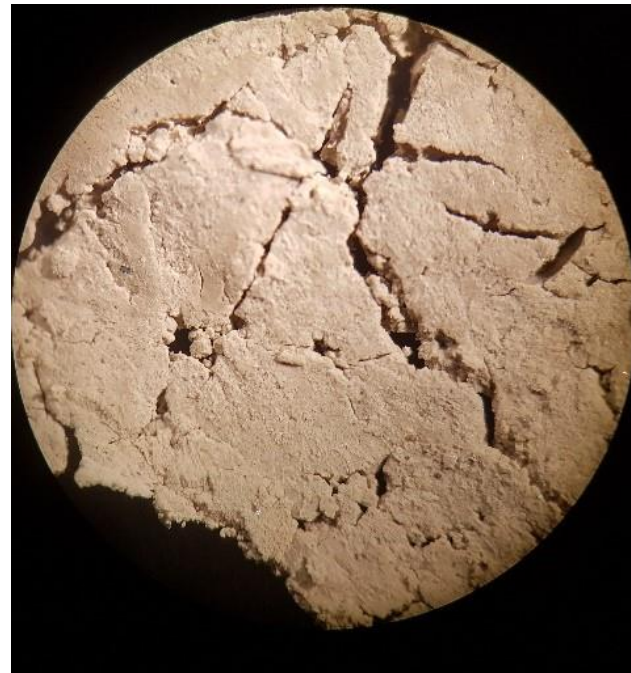

Figure 35: Zoom of 16 .

initial state and these were wider, as shown in Figures 34,35 and 36.

\subsection{Shear Tests}

Due to the loss of samples, only 24 post-thawing shear tests were conducted. Some tests were carried

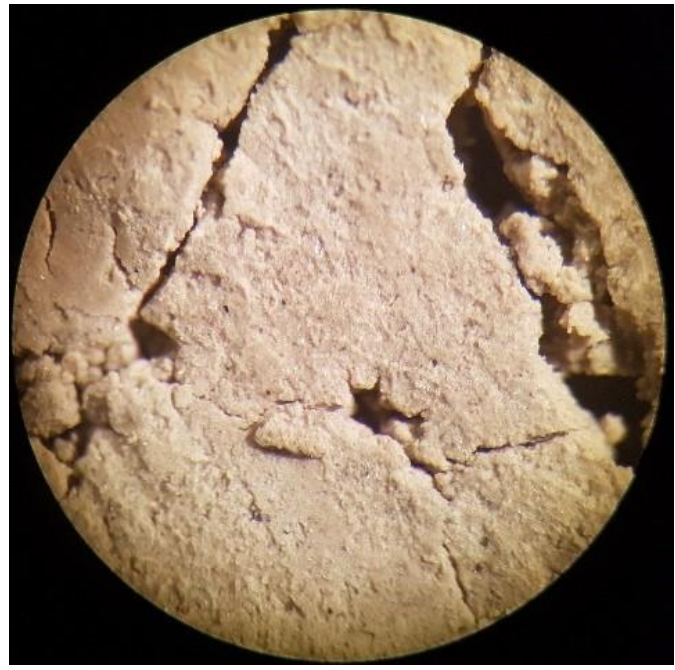

Figure 36: Zoom of 40 .

out on several samples because the condition of some samples did not allow the three points necessary for the direct shear test. Table 8 summarises the values obtained.

According to Table 8, the mean value of $\varphi$ after the thaw is $29.07^{\circ}$ with a standard deviation of $6.89^{\circ}$. The

Table 8: Parameters Summarize of Shear Tests After Thawing

\begin{tabular}{|c|c|c|c|c|}
\hline Sample & $\varphi\left[\left[^{\circ}\right]\right.$ & $C\left[\mathrm{kN} / \mathrm{m}^{2}\right]$ & Correlation [-] & Water Content [\%] \\
\hline$E-H$ & 22.03 & 20.47 & 0.9957 & $20.05 \%$ \\
\hline$I-Q$ & 28.75 & 59.83 & 0.9966 & $17.00 \%$ \\
\hline$K-I$ & 36.12 & 24.86 & 0.9789 & $17.65 \%$ \\
\hline Q-S & 18.83 & 78.98 & 0.9999 & $17.12 \%$ \\
\hline $\mathbf{R}$ & 38.28 & 28.23 & 0.9978 & $16.38 \%$ \\
\hline $\mathbf{T}-\mathbf{Y}$ & 30.25 & 56.03 & 0.9871 & $16.74 \%$ \\
\hline $\mathbf{W}-\mathbf{V}-\mathbf{Z}$ & 34.23 & 49.04 & 0.9923 & $16.40 \%$ \\
\hline$Y-X$ & 26.55 & 55.97 & 0.9533 & $16.89 \%$ \\
\hline $\mathrm{AE}-\mathrm{AF}$ & 26.62 & 14.48 & 0.9895 & $19.79 \%$ \\
\hline$A G-A H-A D$ & 28.82 & 11.46 & 0.9813 & $20.20 \%$ \\
\hline$A H-A L$ & 25.76 & 13.77 & 0.9919 & $19.92 \%$ \\
\hline $\mathrm{AK}-\mathrm{Al}$ & 28.83 & 9.58 & 0.9973 & $19.97 \%$ \\
\hline$A M-A J-A D$ & 27.1 & 10.91 & 0.9984 & $19.70 \%$ \\
\hline$A P-A Q-A R$ & 23.14 & 35.43 & 0.9971 & $18.30 \%$ \\
\hline$A R-A V$ & 27.37 & 42.42 & 0.9933 & $18.03 \%$ \\
\hline AS - AP & 18.7 & 50.45 & 0.8619 & $18.20 \%$ \\
\hline AT - AU & 21.3 & 49.44 & 0.9002 & $18.37 \%$ \\
\hline Average & 29.07 & 35.93 & 0.9637 & $18.03 \%$ \\
\hline
\end{tabular}


soil cohesion is $35.93 \mathrm{kN} / \mathrm{m}^{2}$, with a standard deviation of $21.25 \mathrm{kN} / \mathrm{m}^{2}$. The correlation of all the results was excellent (> 96\%). However, the water content is lower than initially expected. It is $18 \%$ instead of $20.9 \%$. The water lost during the thawing process was certainly due to the ice lenses thawing.

The variation of the results of $c$ and $\varphi$ is very important, although the correlation of each test is good. The values of cohesion were particularly heterogeneous, with values between $4.53 \mathrm{kN} / \mathrm{m}^{2}$ to $78.98 \mathrm{kN} / \mathrm{m}^{2}$. The values of friction angle were also varying noticeably, but to a lesser extent. Except for some atypical values (e.q. $\varphi=47.15^{\circ}$ ), values for $\varphi$ were mainly between 23 to $29^{\circ}$.

\subsection{Oedometric Tests}

Three CRS oedometric tests were carried out on the samples after thawing. The results obtained are shown in Figure $\mathbf{3 7}$ and Tables $\mathbf{9}$ and 10. The void ratios of the three oedometric curves were different. However, the general appearance of the curves was similar,with the exception of the first loading in test 3 , which showed a significant void in an old ice lens (Figure 38). Swelling indexes $c_{s}$ and compression indexes $c_{c}$ showed very close values, except for the value of the compression index in Test 3, which is higher because of the void of ice lens.

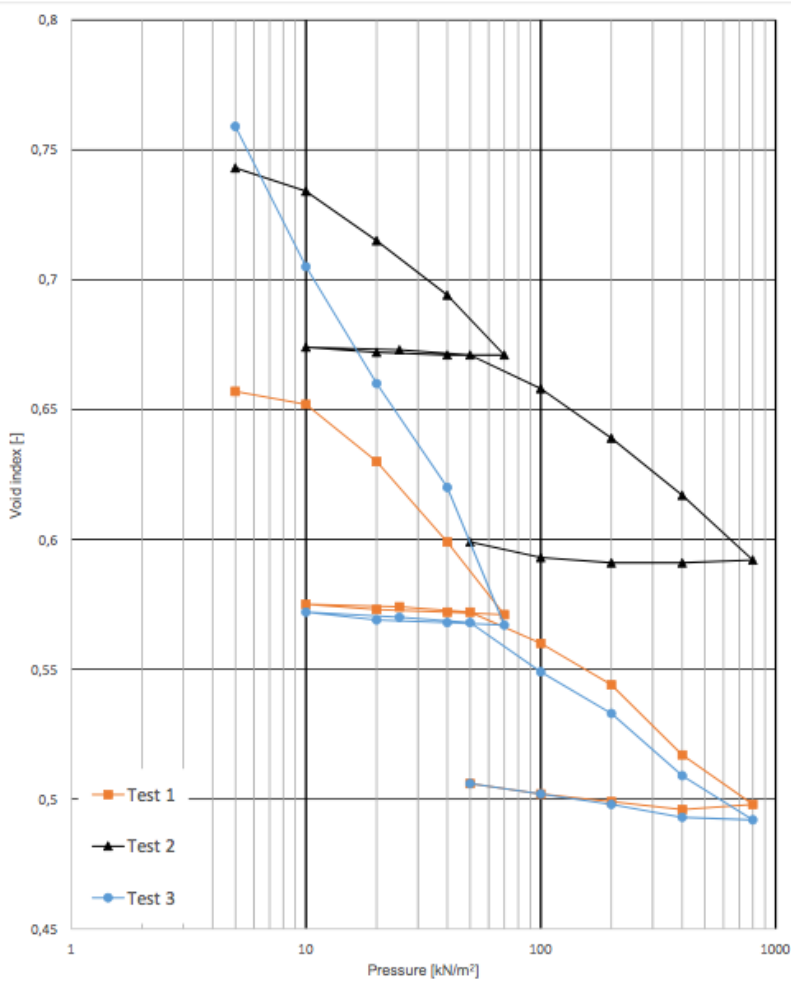

Figure 37: Oedometric curves after thawing.
Table 9: Compression Parameters After Thawing

\begin{tabular}{|c|c|c|c|c|}
\hline & $\boldsymbol{\sigma}_{\text {initial }}^{\prime}\left[\mathbf{k N} / \mathbf{m}^{2}\right]$ & $\mathbf{e}_{0}[-]$ & $\mathbf{c}_{\mathbf{c}}[-]$ & $\mathbf{c}_{\mathbf{s}}[-]$ \\
\hline \hline Test 1 & 70 & 0.675 & 0.082 & 0.0043 \\
\hline Test 2 & 70 & 0.753 & 0.077 & 0.0043 \\
\hline Test 3 & 70 & 0.818 & 0.108 & 0.0057 \\
\hline
\end{tabular}

Figure 39 shows the vertical compression for the tests after thawing. The maximum vertical compression in test 3 is almost twice as high as in tests 1 and 2, which are very similar. For a pressure of $800 \mathrm{kN} / \mathrm{m}^{2}$, the vertical compression in test 3 is $17.93 \%$ while for test 1 and 2 values are of $10.57 \%$ and $9.17 \%$, respectively.

For the same reasons explained in Section 3.7, the values of the compressibility coefficient for stress level, ranging of 10 to $25 \mathrm{kN} / \mathrm{m}^{2}$ and 25 to $50 \mathrm{kN} / \mathrm{m}^{2}$, are skewed.

The soil oedometric modulus, Eoed, was between $1.029 \mathrm{MN} / \mathrm{m}^{2}$ and $2.287 \mathrm{MN} / \mathrm{m}^{2}$ for the initial stress. This value increased to $28.048 \mathrm{MN} / \mathrm{m}^{2}$ to 42.776 $\mathrm{MN} / \mathrm{m}^{2}$ for a stress level of $800 \mathrm{kN} / \mathrm{m}^{2}$.

\section{DISCUSSION}

Results of CRS tests highlight impacts of the freezing on the geotechnical parameters (Figure 40). As expected, the values of the void ratios were higher after a freezing phase. Nevertheless, it was difficult to quantify with precision this increase with the CRS test. The increase in the initial void ratio was local and it was even more important in areas where ice lenses had formed. Outside of these areas, void ratios did not vary in a meaningful way. However, it must be considered that the tested specimens were very small compared to the entire drill core: the height of a sample for the oedometric test was $20 \mathrm{~mm}$, whereas the height of the entire drill core was 140 to $160 \mathrm{~mm}$. Only 12 to $14 \%$ of the specimens were tested. The results were very dependent on the sampling and by the presence, or not, of a void due to an ice lens.

The results of the three CRS oedometric tests after the frozen phase were very variable and confirm what was stated above. Initial void ratios $e_{0}$ for tests 1 and 3 (respectively 0.753 and 0.818 ) were much higher than the values in the test before the frozen phase $(0.680)$. Figures 41 and 42 show the ice lens void on the samples. Test 2 gives different results from test 1 and 
Table 10: Compression Parameters After Thawing

\begin{tabular}{|c|c|c|c|c|c|c|c|c|c|c|}
\hline $\begin{array}{c}\text { Stress level } \\
\text { [kN/m2] }\end{array}$ & $\begin{array}{c}\Delta \sigma \\
{[k N / m 2]}\end{array}$ & e1[-] & $\begin{array}{c}\mathrm{mv} 1 \\
{[\mathrm{~m} 2 / \mathrm{MN}]}\end{array}$ & $\begin{array}{c}\text { Eoed 1 } \\
\text { [MN/m2] }\end{array}$ & e2 [-] & $\begin{array}{c}\mathrm{mv} 2 \\
{[\mathrm{~m} 2 / \mathrm{MN}]}\end{array}$ & $\begin{array}{c}\text { Eoed 2 } \\
\text { [MN/m2] }\end{array}$ & e3 [-] & $\begin{array}{c}\mathrm{mv} 3 \\
{[\mathrm{~m} 2 / \mathrm{MN}]}\end{array}$ & $\begin{array}{r}\text { Eoed 3 } \\
{[\mathrm{MN} / \mathrm{m} 2]}\end{array}$ \\
\hline \multirow[t]{2}{*}{5} & & \multirow{2}{*}{0.657} & & & 0.743 & & & 0.759 & & \\
\hline & 5 & & 0.597 & 1.675 & & 1.027 & 0.974 & & 5.941 & 0.168 \\
\hline \multirow[t]{2}{*}{10} & & \multirow[t]{2}{*}{0.652} & & & \multirow[t]{2}{*}{0.734} & & & \multirow[t]{2}{*}{0.705} & & \multirow[b]{2}{*}{0.404} \\
\hline & 10 & & 1.313 & 0.761 & & 1.084 & 0.923 & & 2.475 & \\
\hline 20 & \multirow{2}{*}{20} & 0.630 & & & 0.715 & & & 0.660 & & \\
\hline & & & 0.925 & 1.081 & & 0.599 & 1.670 & & 1.100 & 0.000 \\
\hline 40 & & 0.599 & & & 0.694 & & & 0.620 & & \\
\hline 70 & & 0.571 & & & 0.671 & & & 0.567 & & \\
\hline & 30 & & - & - & & - & - & & - & - \\
\hline 40 & & 0.572 & & & 0.671 & & & 0.568 & & \\
\hline 20 & & 0.573 & & & 0672 & & & 0569 & 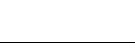 & 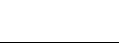 \\
\hline & 10 & & - & - & & - & - & & - & - \\
\hline 10 & & 0.575 & & & 0.674 & & & 0.572 & & \\
\hline & 15 & & 0.040 & 25.125 & & 0.038 & 26.295 & & 0.073 & 13.635 \\
\hline 25 & & 0.574 & & & 0.673 & & & 0.570 & & \\
\hline & & & & & & & & & & \\
\hline 50 & 50 & 0.572 & 0110 & م70 & 0.671 & 014 & 6710 & 0.568 & ? & 470 \\
\hline 100 & & 0.560 & & & 0.658 & & & 0.549 & & \\
\hline & 100 & & 0.096 & 10.469 & & 0.108 & 9.226 & & 0.088 & 11.363 \\
\hline 200 & & 0.544 & & & 0.639 & & & 0.533 & & \\
\hline & 200 & & 0.081 & 12.407 & & 0.063 & 15.936 & & 0.066 & 15.150 \\
\hline 400 & & 0.517 & & & 0.617 & & & 0.509 & & \\
\hline & 400 & & 0.028 & 35.263 & & 0.036 & 28.048 & & 0.023 & 42.776 \\
\hline 800 & 400 & 0.490 & - & - & 0.592 & - & - & 0.492 & - & - \\
\hline 400 & & 0.496 & & & 0.591 & & & 0.493 & & \\
\hline 000 & & & & & & & & & & \\
\hline 200 & 100 & 0.499 & - & - & 0.591 & - & - & 0.498 & - & - \\
\hline 100 & & 0.502 & & & 0.593 & & & 0.502 & & \\
\hline 50 & 30 & 0.506 & - & - & 0.599 & - & - & 0.506 & 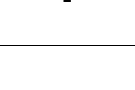 & - \\
\hline
\end{tabular}

3. Indeed, the initial void ratio of test 2 was practically equal to the one given by the CRS test before the frozen phase ( 0.675 for the test 2). Sample 2 was taken in an area without ice lens, as shown in Figure 43, and this is why the void ratio did not vary too much from the initial state.

The calculation of the compression index of curve $\mathrm{n}^{\circ} 3$ was tricky because of its shape on the first loading until the initial stress. In fact, this part of the curve was distinguished from the others by a steeper slope. This behaviour was explained by a higher initial void ratio $\mathrm{e}_{0}$ (about 20\% higher than the initial void ratio of the curve before freezing). Nevertheless, the behaviour of curve $\mathrm{n}^{\circ} 3$ became similar to the other curves on the second loading until $800 \mathrm{kN} / \mathrm{m}^{2}$. The shape of the curves $n^{\circ} 1$ and $n^{\circ} 2$ before freezing were very similar; only the 
compression index $\mathrm{C}_{c}$ of curve $\mathrm{n}^{\circ} 3$ was different from the others. It should be noticed that the effect of the freezing on the swelling index $C_{s}$ was negligible, according to these first tests.

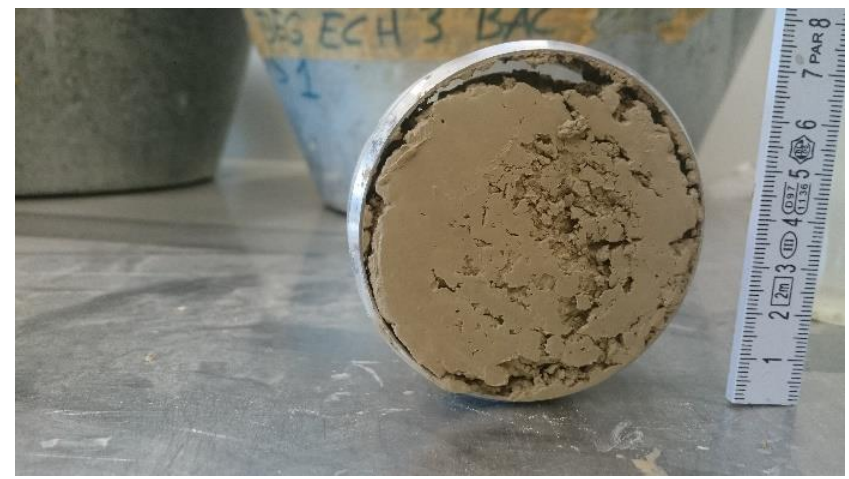

Figure 38: Specimen 3 with voids caused by ice lens.

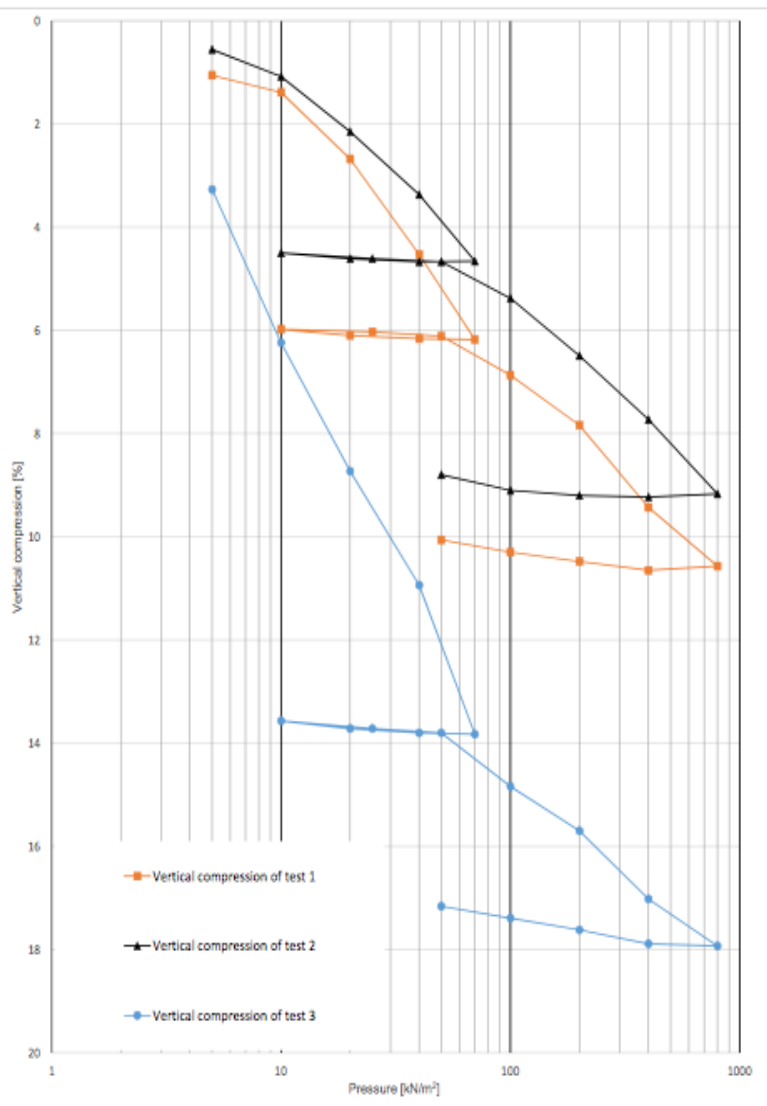

Figure 39: Vertical compression of tests after thawing.

By comparing the curves before and after freezing, it seems as if there is a translation of the initial curve downwards. This behaviour suggests a greater compressibility of the silt after a frozen phase, which is due to the remains of ice lenses developed during the freezing of the soil. Figure $\mathbf{4 4}$ shows the vertical compression of the four curves.

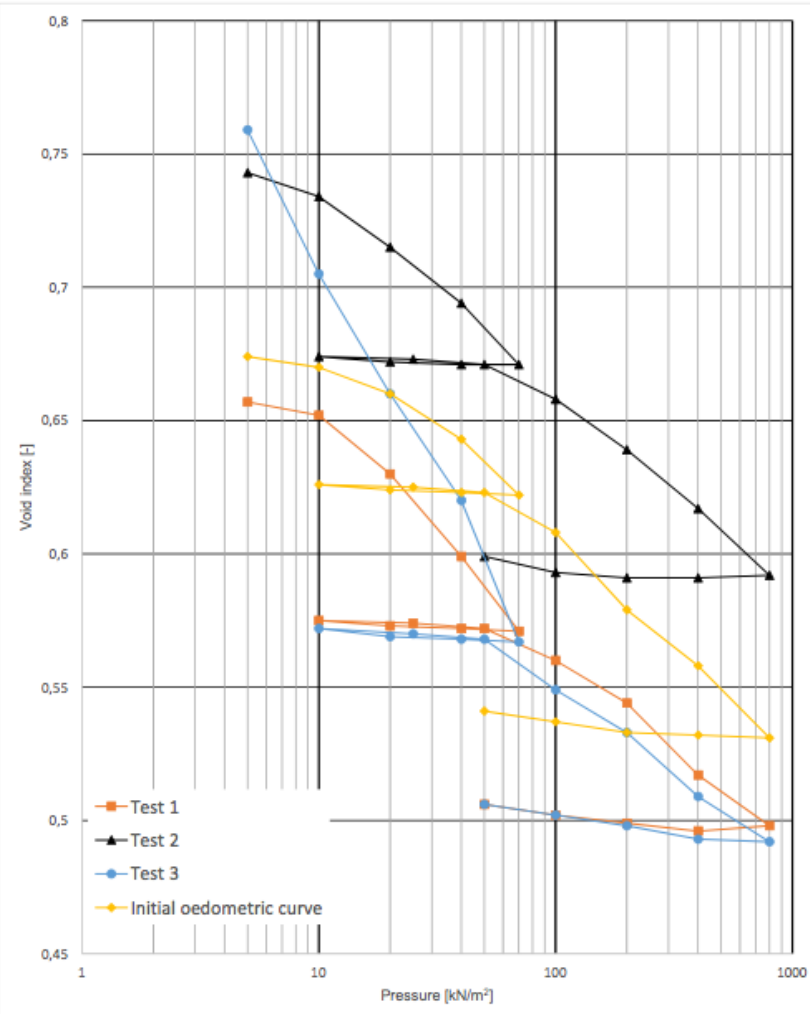

Figure 40: Oedometric curves.

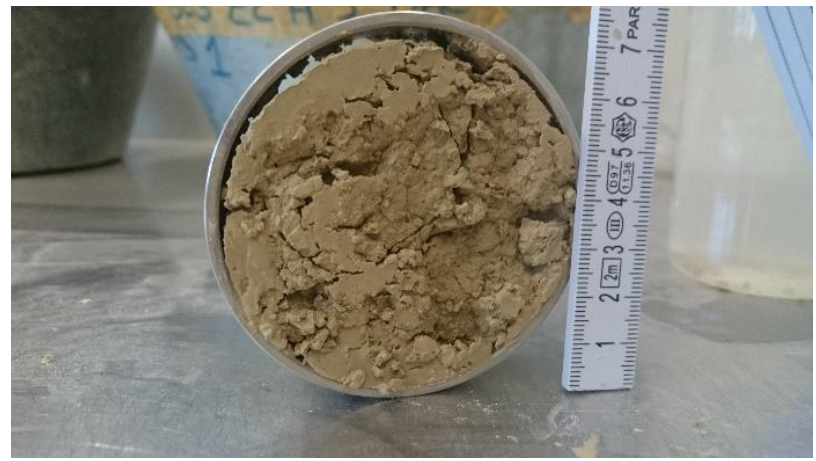

Figure 41: Sample before CRS test 1.

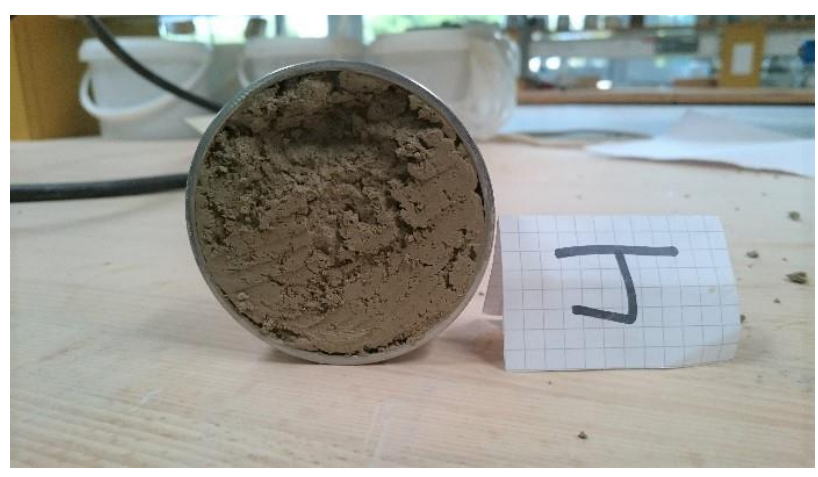

Figure 42: Sample before CRS test 3.

As expected, all tests carried after thawing had a higher compressibility. Nevertheless, this increase was 


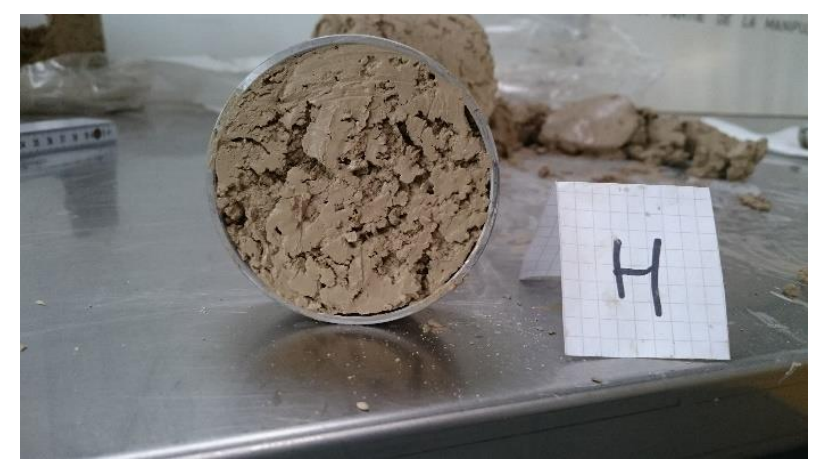

Figure 43: Sample before CRS test 2.

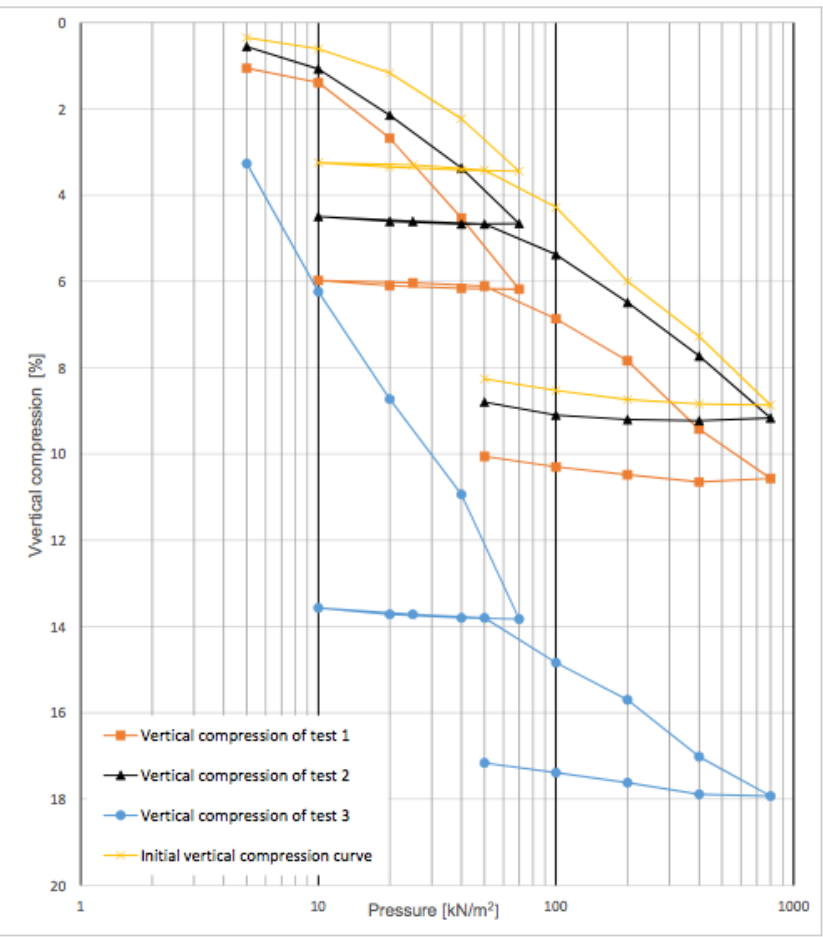

Figure 44: Vertical compression curves.

difficult to quantify with precision. For a pressure of $800 \mathrm{kN} / \mathrm{m}^{2}$, the vertical compression average increased by $41 \%(19 \%$ for test $1,3 \%$ for test 2 and $102 \%$ for test 3). The difference between these values is very large. Therefore, the average value of $41 \%$ must be taken into account with caution. Nevertheless, there is no doubt that the compressibility of the ground after a thaw phase increases significantly. This can lead to problems of settlement for infrastructures built on permafrost that is destined to thaw. In addition, this value matches with a study conducted in the United States on Chicago Blue Clay by Swan et al. (2013).

"Consolidation tests show that one cycle of freezethaw Chicago Blue Clay led to a $25 \%$ to $40 \%$ increase in deformation during consolidation when compared to the deformation of $\mathrm{CBC}$ in its natural state". [4]
Figure 45 shows the evolution of the oedometric modulus in the four tests performed. The yellow curve is the oedometric modulus curve before a frozen phase. An atypical value of the oedometric modulus at the pressure of $150 \mathrm{kN} / \mathrm{m}^{2}$ can be observed. The value at this point is lower than expected. Another atypical value is the first point of the oedometric modulus curve 1. The value is higher than expected. It is reasonable to believe that this value should be between the values corresponding to the first point of curve $n^{\circ} 2$ and the first point of curve $n^{\circ} 3$.

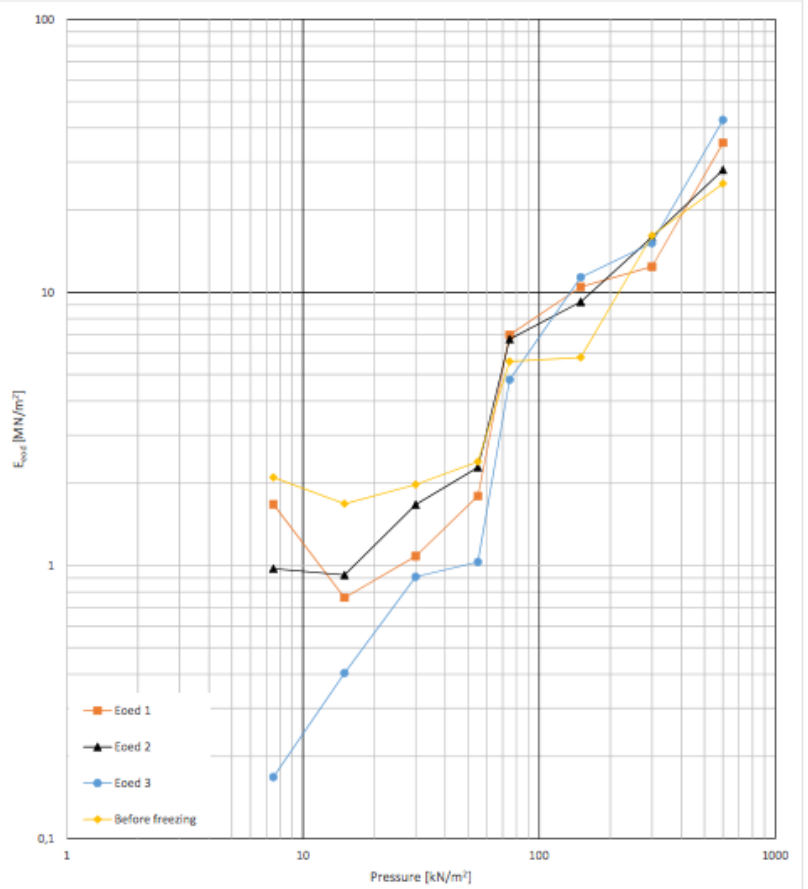

Figure 45: Oedometric modulus curves.

For a pressure corresponding to the initial stress or lower, oedometric modulus values were lower after a freezing/thawing phase. As expected, the voids left by the ice lenses had a direct impact on the values of the oedometric moduli. The higher the void ratios, the lower the oedometric moduli. Figure $\mathbf{4 5}$ illustrates this phenomenon.

According to Figure 45, from the inital stress to 300 $\mathrm{kN} / \mathrm{m}^{2}$, the behaviour of the oedemetric moduli is similar. The gap between the curves decrease, while values increase from $6 \mathrm{MN} / \mathrm{m}^{2}$ to $16 \mathrm{MN} / \mathrm{m}^{2}$.

Beyond $300 \mathrm{kN} / \mathrm{m}^{2}$ a peculiar phenomenon is observed: the trend of the curves is reversed. Curves with the highest void ratios have the highest oedometric moduli. The oedometric modulus of test 3 (test with the highest percentage of voids) is 1.7 times higher than the test before freezing. Values in test 1 
and test 2 are, respectively, 1.4 and 1.1 times higher than in the test before freezing. It would be interesting to carry out additional tests, such as triaxial tests, to possibly confirm this phenomenon.

Figure 46 shows the Mohr Coulomb diagram for the average of the three states (before freezing, during freezing and after thawing).

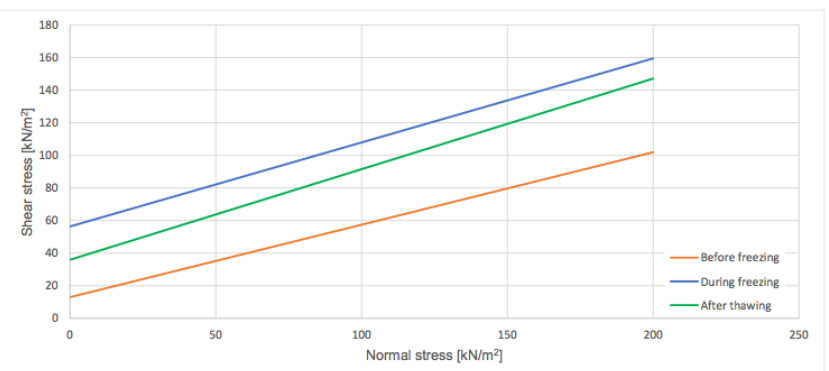

Figure 46: Mohr-Coulomb diagram of the average of the three state.

The results of the shear tests showed that the parameters $c$ and $\varphi$ vary a lot between the phases before freezing, during freezing and after thawing. When the sample froze, the cohesion increased sharply, from $13.0 \mathrm{kN} / \mathrm{m}^{2}$ to $56.3 \mathrm{kN} / \mathrm{m}^{2}$. The angle of internal friction increased as well, but to a lesser extent: $24.0^{\circ}$ to $27.7^{\circ}$. In frozen conditions, the cohesion of the soil increased by more than $300 \%$, and the internal friction angle increased by $15 \%$. This is easily explained by the freezing of the soil. However, these results should be considered with caution because only one shear test was performed on frozen soil.

The interesting phenomenon is that the soil parameters (c and $\varphi$ ) did not return to their initial conditions when the soil thaws. In fact, the cohesion after the freezing/thawing phase decreased because the ice lenses disappeared. However, the cohesion remained higher compared to her initial state. The average cohesion of the 24 shear tests carried out was $35.9 \mathrm{kN} / \mathrm{m}^{2}$. There was a decrease of $36.2 \%$ compared to the frozen state. However, the cohesion remained higher than 2.5 compared to the initial state. When the ice lenses are formed, the soil between two ice lenses is compressed. Therefore, the cohesion increased due to this phenomenon.

The internal friction angle also increased to a value of $29.1^{\circ}$. It is possible that the frost caused a rearrangement of the solid particles that constitute the soil. This may further cause an increase in the friction angle, but it remains only a hypothesis that should be confirmed by complementary analyses.
The system to keep the water content constant throughout the freeze and thaw was not perfect. The water content of the samples on which the shear tests were performed varied of a few percent. However, this allowed to determine the cohesion curve as a function of the water content and the internal friction angle also as a function a function of the water content. Figure $\mathbf{4 7}$ shows the cohesion according to the water content.

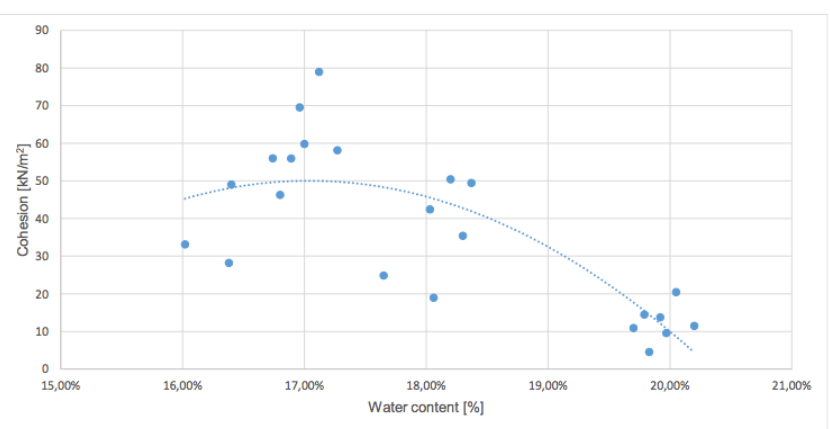

Figure 47: Cohesion according to the water content.

A trend curve looking slightly like the Proctor curve was observed, with an optimum cohesion around $17 \%$ water content. This is intriguing because this water content is relatively close to the optimum Proctor water content. The closer the water content is to the saturation of the soil, the lower the cohesion. On the other hand, despite the theory that soil cohesion might follow a proctor-like curve is interesting, this result needs to be further investigated. However, there were two atypical values with cohesion too low in relation to the trend curve (cohesion between 19 and $25 \mathrm{kN} / \mathrm{m}^{2}$ for a water content between 17.5 and 18\%).

Figure 48 illustrates the values of the friction angle as a function of the water content. The trend in this case has the shape of an inverted bell. The minimum of the curve would also be at a water content close to the Proctor optimum. The same atypical values in Figure 47 can also be observed in Figure 48.

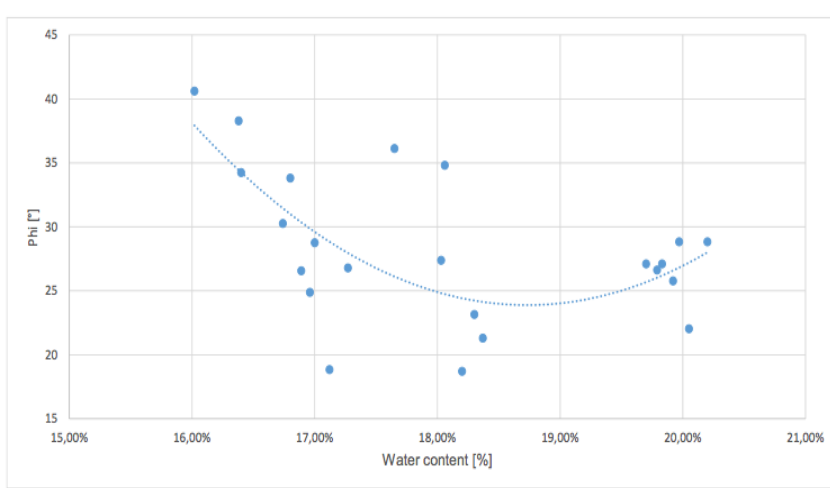

Figure 48: Phi according to the water content. 
These observations were possible because the water content of the samples after thawing was not constant. Nevertheless, more test results are needed to confirm or invalidate this assumption.

\section{CONCLUSIONS}

This work aimed to perform a preliminary study of the effects of the phenomenon of freezing/thawing on a silty soil, analysing the possible variations of the shear strength characteristics and compressibility properties of the soil itself.

First, a complete soil characterisation was performed in terms of granulometry, Atterberg limits, optimal water content and bulk density. Specimens of soil were prepared and shear and oedometric tests were carried out on the soil before freezing in order to define a reference case.

Then, the specimens were subjected to an 18-day freezing phase with following thawing. The results of oedometric tests suggest an increase of the compressibility properties of the soil.

The results provided from the CRS oedometric test show a significant increase in the compressibility properties of the soil. Under a stress level of 800 $\mathrm{kN} / \mathrm{m}^{2}$, the average compressibility in the three tests increased by $41 \%$.

Shear tests showed a decrease of $36.2 \%$ of soil cohesion when it thawed. The internal friction angle increased slightly $\left(27.7^{\circ}\right.$ to $\left.29.1^{\circ}\right)$.

The results obtained by the shear tests, oedometrics tests and the observation of the samples make it possible to conclude that a strong decrease of the bearing capacity of the soil occurs when the soil thaws. Loss of soil bearing capacity due to changes in the cohesion and internal friction angle can cause severe damage to structures based on frozen ground. Increasing the compressibility of the soil can also pose serious problems, especially in cases of differential settlements. Depending on the exposure of the structures (roads, ski area, mountain chalet, etc.) to the hazards related to permafrost thawing, plans for strengthening foundations should be set up.

In addition, this preliminary study may be useful for research in the field of natural hazards in permafrost areas. Indeed, many researches have been carried out to assess the impact of global warming on the frequency of occurrence of natural hazards in Alpine areas (mudflows, landslides, boulder falls, debris flow, etc.). The results on the evolution of the geomechanical parameters of the soils in this study can help researchers to better understand this Phenmenon.

Understanding the impacts of permafrost thaw is however very complex. For this reason, further studies following up this project are strongly recommended. The number of oedometer tests should be increased in order to establish more accurate statistical elaborations. It would also be desirable to carry out triaxial tests, as well as tests on the evolution of permafrost permeability.

The more studies carried out on this subject, the more it will be possible to understand the impact of global warming on permafrost and, therefore, on environment and human lives.

\section{ACKNOWLEDGEMENTS}

The authors would like to thank Eric Bedelek, scientific collaborator at the HEIG-VD, for his help in collecting samples and his advice and Dr. Jacopo Abbruzzese, HES assistant, for the time to discuss about this project.

\section{NOTATION}

$$
\begin{aligned}
& \mathrm{C}_{c}=\text { compressibility index } \\
& \mathrm{C}_{\mathrm{s}}=\text { swelling index } \\
& \mathrm{C}_{\mathrm{V}}=\text { coefficient of consolidation } \\
& \mathrm{C}=\text { cohesion } \\
& \mathrm{d}=\text { particle size } \\
& \mathrm{E} \quad=\text { compaction energy } \\
& \mathrm{E}_{\text {eod }}=\text { oedometric moduls } \\
& \mathrm{e} \quad=\text { void ratio } \\
& \mathrm{e}_{0} \quad=\text { initial void ratio } \\
& \mathrm{H}=\text { height of fall } \\
& \mathrm{H}_{\mathrm{r}}=\text { effective depth of the aerometer centre of } \\
& \mathrm{I}_{\mathrm{P}} \quad=\text { thrust } \\
& \mathrm{m} \quad=\text { masticity index }
\end{aligned}
$$




$$
\begin{aligned}
& \mathrm{m}_{\mathrm{g}}=\text { mass in water } \\
& \mathrm{m}_{\mathrm{v}}=\text { compressibility coefficient } \\
& \mathrm{m}_{\mathrm{w}}=\text { mass with paraffin } \\
& \mathrm{n}=\text { hits number } \\
& \mathrm{P} \quad=\text { hammer weight } \\
& \mathrm{S}_{\mathrm{r}}=\text { degree of saturation } \\
& \mathrm{t}=\text { time } \\
& \mathrm{V}=\text { volume } \\
& \mathrm{WL}=\text { liquidity limit } \\
& W_{P}=\text { plasticity limit } \\
& \gamma=\text { bulk density } \\
& \gamma_{\mathrm{s}}=\text { solid particle density } \\
& \rho \quad=\text { density of materiel } \\
& \rho_{\mathrm{d}} \quad=\text { dry density of materiel } \\
& \sigma \quad=\quad \text { stress level } \\
& \varphi=\text { internal friction angle }
\end{aligned}
$$

\section{REFERENCES}

[1] Dysli M. Swiss philosophy and developments concerning the loss of bearing capacity during thaw, Lausanne: Soil mechanics laboratory Swiss Federal Institute of Technology, 1982.

[2] Dysli M. Le gel et son action sur les sols de fondations, Lausanne: Presses polytechniques et universitaires romandes, 1991.

[3] Dysli M. Etude expérimentale du dégel d'un limon argileux. Application aux chaussées et pergélisols alpins, Lausanne, 2007.

[4] Swan CW, Grant A, Kody A. Characteristics of Chicago Blue Clay subjected to a freeze-thaw cycle. In Mechanical properties of frozen soils, H. Zubeck and Z. Yang, Eds., West Conshohocken : ASTM International, 2013; pp. 22-32. https://doi.org/10.1520/STP156820130015

[5] Chamberlain EJ. A freeze-thaw test to determine the frost susceptibility of soils, Hanover: US Army, Corps of Engineers, Cold Regions Research \& Engineering Laboratory, 1987.

[6] Qi J, Vermeer PA, Cheng G. A review of the influence of freeze-thaw cycles on soil geotechnical properties," Permafrost and Periglacial Proc. 2006;17: pp. 245-252. https://doi.org/10.1002/ppp.559

[7] Bigl SR, Shoop SA. Soil moisture prediction during freeze and thaw using a coupled heat and moisture flow model. Hanover, New Hampshire : US Army, Corps of Engineers, Cold Regions Research \& Engineering Laboratory, 1994.

[8] Steiner A, Vardon PJ, Borere W. The influence of freeze-thaw cycles on the shear strength of illite clay. Proceedings of the Institution of Civil Engineers - Geotechnical Engineering, February 2018; pp. 16-27.

https://doi.org/10.1680/jgeen.16.00101

[9] C. VSS, SN 670 345b, Zürich: Association Suisse des professionnels de la route et des transports, 2008.

[10] C. VSS, SN 670 330-2, Zürich: Association Suisse des professionnels de la route et des transports, 2015.

[11] C. VSS, SN 670 340-10, Zürich: Association Suisse des professionnels de la route et des transports, 2008.

[12] C. VSS, SN 670 340-2, Zürich: Association Suisse des professionnels de la route et des transports, 2008.

[13] C. VSS, SN 670 340-5, Zürich: Association Suisse des professionnels de la route et des transports, 2008.

[14] C. VSS, SN 670 816a, Zürich: Association Suisse des professionnels de la route, 1990.

[15] C. VSS, SN 670 902-1b, Zürich: Association Suisse des professionnels de la route et des transports, 2007.

[16] C. VSS, SN 70 140b, Zürich: Association Suisse des professionnels de la route et des transports, 2019.

[17] van Huissteden J. Thawing Permafrost, Springer International Publishing, 2020. https://doi.org/10.1007/978-3-030-31379-1

[18] Yamamoto $Y$. Instabilities in alpine permafrost: strength and stiffness in a warming regime, Regime Band 2014; 243.

[19] Nötzli J. Modeling transient three-dimensional temperature fields in mountain permafrost, Zürich: Geographisches Institut der Universität Zürich, 2011.

[20] Harris SA, Brouchkov A, Guodong C. Geocryology characteristics and use of frozen ground and permafrost landforms, Boca Raton : CRC Press, 2018. https://doi.org/10.4324/9781315166988

Received on 30-03-2020

DOI: https://doi.org/10.15377/2409-5710.2020.07.1

(C) 2020 Howald and Torche; Avanti Publishers.

This is an open access article licensed under the terms of the Creative Commons Attribution Non-Commercial License (http://creativecommons.org/licenses/by-nc/3.0/) which permits unrestricted, non-commercial use, distribution and reproduction in any medium, provided the work is properly cited. 